\title{
Fuel poverty and low carbon emissions: a comparative study of the feasibility of the hybrid renewable energy systems incorporating combined heat and power technology
}

(C) The Author(s) 2021. This article is published with open access at link.springer.com and journal.hep.com.cn

\begin{abstract}
Fuel poverty is most prevalent in North East England with $14.4 \%$ of fuel poor households in Newcastle upon Tyne. The aim of this paper was to identify a grid connected renewable energy system coupled with natural gas reciprocating combined heat and power unit, that is cost-effective and technically feasible with a potential to generate a profit from selling energy excess to the grid to help alleviate fuel poverty. The system was also aimed at low carbon emissions. Fourteen models were designed and optimized with the aid of the HOMER Pro software. Models were compared with respect to their economic, technical, and environmental performance. A solution was proposed where restrictions were placed on the size of renewable energy components. This configuration consists of $150 \mathrm{~kW}$ CHP, $300 \mathrm{~kW}$ PV cells, and $30 \mathrm{~kW}$ wind turbines. The renewable fraction is $5.10 \%$ and the system yields a carbon saving of $7.9 \%$ in comparison with conventional systems. The initial capital investment is $\$ 1.24$ million which enables the system to have grid sales of $582689 \mathrm{kWh} / \mathrm{a}$. A conservative calculation determined that $40 \%$ of the sales can be used to reduce the energy cost of fuel poor households by $\$ 706$ per annum. This solution has the potential to eliminate fuel poverty at the site analyzed.
\end{abstract}

Keywords greenhouse gas control, low carbon target, grid connected, renewable fraction, fuel poverty, combined heat and power, HOMER Pro

Received Jun. 5, 2020; accepted Jan. 4, 2021; online Jul. 10, 2021

Dorota RZETELSKA, Madeleine COMBRINCK $(\bowtie)$

Department of Mechanical and Construction Engineering, Faculty of Engineering and Environment, Northumbria University, Newcastleupon-Tyne, NE1 8ST, UK

E-mail: madeleine.combrinck@northumbria.ac.uk

\section{Introduction}

Fuel poor households account for $11.1 \%$ of the dwellings in England. There are several schemes and policies in place to address the problem; however, fuel poverty rate increases steadily. Solutions proposed by the Government, Winter Payment and Warm Home Discount for example, reach only $10 \%$ of those in fuel poverty. Other initiatives such as improving energy efficiency of the housing stock in fuel poverty require substantial funding [1]. There is a need for innovative solutions to utilize low carbon technologies and energy saving measures to meet multiple objectives. Fuel poverty solutions that also address climate change by utilizing renewable energy sources and emission saving technologies may prove to be financially and technically feasible. Such innovations not only reduce carbon dioxide emissions, but also create opportunities to utilize financial gains from energy generation toward helping to reduce fuel poverty for qualifying tenants.

The aim of this paper was to identify a technically and economically feasible grid and combined heat and power connected hybrid renewable energy system with a potential to help alleviate fuel poverty that would also meet the Low Carbon Target.

\subsection{Fuel poverty}

Access to electricity and heating is considered as a basic living standard in countries like England. However, 2.551 million $(11.1 \%)$ households were unable to afford satisfactory level of heating in 2018 , with $81.6 \%$ of fuel poor houses located in urban areas [2]. The term 'fuel poverty' was in use as early as in 1970s but a definition that was widely accepted and used was introduced in 2001 in the Fuel Poverty Strategy for the UK, and described a fuel poor household as one where $10 \%$ of the household's income was insufficient to provide energy supply required to keep the house warm [3]. 
Living in dwellings that do not meet the recommended criteria for thermal comfort set up by the World Health Organisation, $21^{\circ} \mathrm{C}$ for a living room and $18^{\circ} \mathrm{C}$ for other rooms, expose tenants to cold, mold and damp that pose significant risks to human health [3]. Tenants affected by fuel poverty become more prone to respiratory tract infections; their pre-existing conditions such as asthma worsen and the risk of getting a heart attack or stroke increases. Fuel poor households are also often affected by debt and subsequent disconnection from energy provision resulting in significant decline in tenant's well-being and their quality of life. Fuel poverty is most often experienced by vulnerable members of the society: the elderly, the sick, the disabled, single parents, and young children [4]. It has been estimated that treating health conditions resulting from living in poor housing cost the NHS (National Health Service) in England £1.4 billion to $£ 2.0$ billion a year. These costs can be significantly reduced and even prevented with a $£ 10$ billion investment toward improvement the housing stock occupied by those who are affected by fuel poverty [5].

Fuel poverty in UK is characterized by regional differences with the South East and East of England the least affected and North East and West Midlands the most affected [6]. In Newcastle upon Tyne, 14.4\% of households are fuel poor [7] with approximately 323 deaths a year resulting from preventable illnesses related to exposure to cold [4]. These deaths could be prevented by providing suitable level of heating and insulation and making fuel prices more affordable. Newcastle City Council recognized that improvement of the households' energy efficiency provides long-term solution that will makes houses cheaper and easier to heat [4].

Several schemes introduced by the Government are in place, such as Winter Fuel Payment, Cold Weather Payment, and Warm Home Discount Scheme, that offer financial support to those who cannot afford adequate level of heating in their homes; other schemes offer a financial assistance in applying energy saving measures e.g., loft insulation or boiler replacement [8].

There are also innovative solutions being investigated or in place aiming to reduce the number of fuel poor households. One of such solutions was implemented in Aberdeen. The poorest members of the community were allocated a flat in a multi-storey accommodation. The fuel poverty rate in these buildings was as high as $70 \%$. Aberdeen Heat and Power (AHP), a non-profit, locally owned and independent energy service company was created to provide an access to affordable heat for social housing, to improve energy efficiency of the multi-storey buildings and to reduce carbon emission. AHP owns, operates, and maintains three CHP energy centers coupled with heat networks delivering $34 \mathrm{MWh}$ of heat per annum. The system established by the AHP supplies 2000 flats located in 26 multi-storey blocks of flats, a school and 12 communal buildings (including sport and leisure center) with a network length of $14 \mathrm{~km}$. A surplus of energy is sold to the grid and the profit is spent on keeping the tariffs low and to maintain a fund for further investments. Heat tariffs applied by the AHP are based on the cost of energy production and not influenced by the energy market. With the system based on CHP and heating network, the cost of heating was reduced by $45 \%$ with a similar level of carbon saving [9].

\subsection{Emission target}

The reliance of fossil fuels on energy generation contributed to climate change that poses a danger to current and future generations. The Government set the targets for emissions and energy generation from renewable energy sources to limit the implications of climate change. It was proposed that emissions need to be reduced by $34 \%$ by 2020 and a minimum of $80 \%$ by 2050 , and that by 2020 approximately $30 \%$ of electricity should be generated from renewable energy sources. To achieve that, the Government planned to invest in improvement of energy efficiency, and development and deployment of renewable energy technologies. The Government offered support to individuals, communities and businesses engaging them in meeting low carbon goals [10].

Low carbon targets also apply to residential housing [5] as the residential buildings have substantial energy demand and contribute significantly to greenhouse gas emission [11]. The energy use of 27.2 million homes in the UK accounts for 19\% of total UK's greenhouse gas emission [5]. To meet the emission targets, it is necessary to renovate and decarbonise the current housing stock [5,11]. Direct carbon dioxide emissions associated with buildings need to fall by a minimum of $24 \%$ by 2030 (when compared to the levels of carbon dioxide in 1990) and the energy consumption required for heating the existing buildings needs to be reduced by $15 \%$ (as compared to the level in 2015) by 2030 as a result of efficiency improvements [5].

As the housing energy demand is on the increase whereas greenhouse emissions from buildings have not been sufficiently reduced, the UK's climate change targets are more challenging to achieve. To make the current housing stock low carbon and climate-resilient, it is necessary for their retrofitting to become a priority for British infrastructure and it needs to be supported financially by the Government [5]. Transition of residential buildings to low carbon ones can be achieved with deployment of renewable energy technologies.

\subsection{Hybrid renewable energy system}

Hybrid renewable energy systems (HRES) are designed to utilize renewable energy technologies and combine them with conventional methods of energy generation and energy storage to overcome the intermittent nature of renewable energy sources in meeting energy demand [12- 
14]. The techno-economic feasibility of such systems relies not only on the availability of renewable energy sources and weather conditions in a given location, but also on policies and regulations in place to support installation and operation of HRES [15].

HRES are often deployed in remote areas, where grid supply is not existing or not feasible, but they can also be utilized in urban areas where the grid connection is established [16]. Raji and Luta [13] and Abdilahi et. al. [15] designed HRES coupled with diesel generators suitable for urban areas. They used the HOMER software to perform techno-economic analysis of proposed systems. Raji and Luta [13] compared the feasibility of grid connected and grid independent HRES, whereas Abdilahi et. al. [15] compared the proposed HRES with the conventional energy generation system. They showed significant benefits of HRES in comparison with the conventional system. With HRES in place, renewable energy penetration was $58 \%$, the cost of energy (COE) decreased by $30 \%$, and the net present cost (NPC) of the proposed HRES was $25 \%$ cheaper than the conventional system based on diesel generators only.

HRES can be designed with various types of generators. Combined heat and power systems (CHP) offer significant energy and carbon savings when sized and operated properly and can be successfully retrofitted into existing buildings [17]. This approach has therefore not only been of interest lately due to the technical benefit, but for the environmental benefit that is associated with it as well [18]. The energy consumed from the grid can be significantly reduced which results in the reduction of $\mathrm{CO}_{2}$ emissions $[19,20]$. The overall benefit of green technologies is increased by using HRES to minimize the cost of energy, lifecycle cost, and the life cycle greenhouse gas emissions in a particular area [21].

\subsection{Combined heat and power}

In a conventional energy generation system, thermal demand is served by a boiler and electric demand is supplied by a power plant. In a combined heat and power energy generation system, thermal demand is met with the heat that is a by-product of power (electric or mechanical) generation that takes place in a CHP unit. With the CHP technology, power generation, and heat recovery, and utilization take place in a single, highly efficient 'cogeneration' process [17,22].

A CHP plant consists of several components. The main one is a prime mover i.e., a heat engine that drives the generator. There are several types of prime movers that can be used in a CHP system: an internal combustion engine, a gas turbine, a steam turbine, combined cycle gas turbine, a Stirling engine, a fuel cell, or organic Rankine cycle. The choice of a prime mover depends on the scale of the CHP and whether the CHP is custom-built or packaged. CHPs are often designed to operate using more than one type of fuel. This approach incurs additional costs, but it offers flexibility, security of supply, and potential financial benefits associated with fluctuating fuel prices. The CHP can meet heat demand as hot water or steam and offers cost-effective solutions suitable for both large and small public, industrial, and commercial settings with an appropriate heat demand [17].

Co-generating CHP uses fuel more efficiently than traditional systems of delivering energy based on the electricity supplied by power stations and the heat delivered from individual boilers. Energy saving comes from the difference in the efficiency of power station generator (around 40\%) as well as the reduced losses of energy in power generation and the distribution process. In power station, energy is lost as heat through cooling towers during the generation process and then further losses occur during transmission. With CHP, losses are minimised as the 'waste' heat is utilized, and transmission losses are significantly reduced with on-site power generation. To deliver the same number of units of electricity and heat, a CHP system needs 100 units of fuel whereas a traditional system comprising of a power station and a boiler need 139 units of energy [17].

A constant thermal load of $4500 \mathrm{~h}$ is required to make CHP units economical. Thus, before a CHP is considered as a suitable system for a given site, an initial assessment must be conducted.

Sizing of the CHP unit is crucial in maximising economic and environmental profits. A correctly sized system leads to a high heat recovery and overall efficiency. A surplus of electricity generated by the system can be sold to the national grid. The CHP needs to be set up to meet the lowest average heat load to achieve a unit that is most economical. The information on thermal and electric loads, and the annual and daily energy profiles must be collected. The heat-to-power ratio that reflects how many units of usable heat will be obtained for every unit of electricity generated by the CHP must also be determined. The heatto-power ratio varies with respect to the type of the prime mover. A ratio of 1.3:1 is typical for reciprocating engine, whereas a ratio of 2.5:1 is seen in gas turbines. The most suitable prime mover can be chosen once the size of the CHP and the heat-to-power ratio are established. The initial assessment of CHP feasibility also includes the analysis of the fluctuation in the price of primary fuel, electricity and gas, and the assessment of the potential capital cost and operational and maintenance costs and the comparison of CHP performance with the system that is already on site. Such analysis will help to establish potential savings that can be achieved with the CHP [17].

On-site CHP has the potential to reduce primary fuel consumption, cost of energy and carbon emissions, and improve energy efficiency. The CHP that can operate independently of the grid and can provide emergency power in case of a failure in supply of energy from the mains ensures the security of energy supply [17]. 
In the conventional system, fuel is spent to generate heat in a boiler. With CHP in place, thermal demand is met without additional fuel required. Thus, $28 \%$ of primary fuel savings can be achieved. Energy bills can be reduced by $20 \%$ to $30 \%$ and the level of carbon savings reach from $30 \%$ $[17,22]$ to $50 \%$ in comparison with systems based on isolated generation of heat and electricity [9]. There is a potential of further carbon savings with replacing fossil fuels used for running CHP with low-carbon alternatives [17].

CHP offers several benefits. However, the capital investment associated with deployment of CHP can be substantial and the payback time may be relatively long. The UK Government introduced several schemes that offered financial and tax support to improve economic feasibility of existing and developing CHP systems $[17,23]$. The incentives offered by the Government include Climate Change Levy Exemption, Carbon Price Support Tax Exemption, Enhanced Capital Allowances, Business Rating Exemption, Renewables Obligations (not available for new CHP schemes), Renewable Heat Incentive, Feedin Tariff, and Hydrocarbon Oil Duty Relief. However only CHP plants approved as 'Good Quality' can benefit from such support [23].

CHP can be successfully coupled with renewable energy technologies. In a study conducted by Ataei et al. [24], the techno-economic performance of the system integrating CHP with the solar PV technology was assessed to improve the energy efficiency of an educational building in Dayton, Ohio, USA. To perform analysis of the CHP-PV system, the researchers used the HOMER software to derive the most optimal design. They analyzed the combined effect of the CHP-PV system and retrofitting energy efficiency measures (e.g., overhangs, natural ventilation, and daylighting) on the building. They achieved a $32.5 \%$ reduction in carbon emissions and the total energy consumption with CHP-PV and energy efficiency measures applied at the same time. With the CHP-PV model optimised in the HOMER software, $46 \%$ of the thermal load was supplied by the CHP and the remaining heating load was met by a boiler. The investment cost covering energy efficiency measures and the CHP-PV system was $\$ 225500$ with a payback time of 5.8 years.

\subsection{Decarbonisation of energy systems}

Two thirds of the heat supply associated with the buildings in urban areas is met by fossil fuel operated onsite boilers. In highly populated areas with sufficient heat demand, individual boilers can be successfully replaced with more energy efficient solutions such as district heating. In the Heat Roadmap Europe Energy Efficiency (HRE-EE) strategy, it was proposed that relatively small decentralised onsite CHP units can become essential in expanding district heating. That would allow excess heat to be utilized more efficiently. The CHP technology, as a part of district heating, can play an important role in decarbonizing the energy sector. With district heating in place, it is possible to achieve a significant reduction in emissions of carbon dioxide at a lower price when compared to other energy efficient solutions [25] and to successfully improve the efficiency of energy supply [11]. Additionally, district heating coupled with thermal storage technologies can significantly improve fuel efficiency of the system [26].

Decarbonisation of energy supply needs to be supported by solutions that allow energy savings on demand-side. Several long-term solutions are being considered: changing customer behavior; implementing near Zero Energy Buildings (nZEB) i.e., highly energy efficient buildings that incorporate renewable energy technologies placed either onsite or nearby; retrofitting the existing building stock, i.e., improving the energy performance of the building elements such as windows, insulation, the ventilation system, and boilers [11].

Redesign of the current system in place is needed to effectively decarbonise the energy sector. A new, smart, and efficient energy system would facilitate transition to $100 \%$ energy obtained from renewable sources addressing its fluctuating nature, be cost-effective and fuel-efficient and it would interconnect different energy sectors $[11,26]$.

Redesign of the Danish energy system proposed by Drysdale et. al. [11] involves three smart grids: smart electricity grid, smart thermal grid, and smart gas grid, and incorporates energy storage solutions to allow integration of electricity, heating, cooling, gas and transport sectors to compensate for the fluctuating nature of the energy obtained from wind and solar technologies. The Smart Energy System employs power and gas infrastructures to allow intelligent integration of the demand and supply, and includes a network of pipes that connect buildings at neighborhood, city center, or the whole city level to distribute the heat or cooling generated by centralised plants, decentralised and individual suppliers [26]. Transition from the energy system based solely on fossil fuels to the system based exclusively on renewable energy involves various strategies. For the Danish energy system, the CHP technology plays an important role in the transition toward the $100 \%$ renewable energy system. CHP allows to couple both power and heat sectors, increases distributed power generation and ownership [27].

\section{Materials and methods}

The HOMER Pro software developed by the National Renewable Energy Laboratory in the USA has been used in several studies to demonstrate the techno-economic feasibility of HRES. The software allows rapid analysis of HRES that are either grid-independent or grid-connected. The software compares thousands of various designs, combining conventional and renewable energy sources with storage systems and load management, with respect to 
dozens of variables in order to identify the most costeffective solution $[28,29]$. It uses the algorithm to determine a system with the lowest net present cost.

CHP has a significant potential to replace the conventional energy system based on separated generation of heat and power. Economic and environmental benefits of the system can possibly be enhanced by coupling CHP with renewable energy technologies. Such system could be then optimized using the HOMER software to identify the HRES design that not only has low net present cost, but also when compared to a conventional energy system, uses less primary fuel, has lower carbon dioxide emissions, meets the renewable electricity target of $30 \%$, and generates profit by selling the surplus of energy to the grid that can be used to help alleviate fuel poverty.

A feasibility study of this nature, that is applicable to Newcastle upon Tyne, UK, has not been performed, to the best knowledge of the authors.

\subsection{Site considerations}

A housing estate located at Stanhope Street in Newcastle upon Tyne, North East of England, was chosen for the simulation (Fig. 1). The initial site survey was performed to assess the number of buildings, their positions as well as to estimate the number of flats.

The site comprises of 10 buildings with flat roofs that is 4 storeys high, with 3 facing north-south, 3 facing northwest, 3 facing north-east, and 1 facing east-west. It was estimated that the estate consisted of 318 flats and maisonettes that were one-, two- and three-bedroom.

No renewable energy technologies were observed on the site at the time of the visit. It was assumed that the estate was connected to the national grid and supported by a central boiler house with natural gas fired boilers, hot water storage, and associated pumps and system controls. It was also assumed that the boiler house was big enough to install a CHP unit with associated pipework, equipment and controls; and the heat generated by the proposed system would be transmitted from the CHP and boiler plant to the flats via underground system of heating network.

The number of households varied between the buildings on the estate, and it was assumed that the dwellings were occupied by single people as well as by families; thus, electric and thermal loads would vary between flats and between the buildings. As the data on the real-life electric and thermal consumption of the estate was not available, the annual average domestic energy consumption of a single household was assumed to be $12300 \mathrm{kWh}$ of gas and $3200 \mathrm{kWh}$ of electricity. These data are based on typical domestic consumption values available from the UK Government Office of Gas and Electricity Markets (OFGEM) [30].

The above values were multiplied by the total number of flats in the housing estate, i.e., 318 , and then divided by 365 to obtain the daily electric and thermal consumption per housing estate, i.e., $10716.1644 \mathrm{kWh}$ and 2787.94521 $\mathrm{kWh}$ (respectively).

The electric and thermal loads of the communal areas such as corridors and staircases were omitted in the load simulation.

It was further assumed that the local energy load distribution of power and heating was as follows: the heat out underground at medium pressure hot water was distributed at a flow rate of $120^{\circ} \mathrm{C}$ (distribution in ducts around the site, below ground level) and return temperature was $100^{\circ} \mathrm{C}$. Then the temperature was assumed to step down via heat exchanger in the building to the rises at the dwellings, and the flow temperature was down to $80^{\circ} \mathrm{C}$ (temperature in radiators) and flow return at $70^{\circ} \mathrm{C}$.

Electricity was generated at $415 \mathrm{~V}$ (three phase) and stepped down to $230 \mathrm{~V}$ (single phase).

\subsection{Renewable energy sources}

The site was surveyed for the possibility of installing renewable energy technologies to introduce electricity

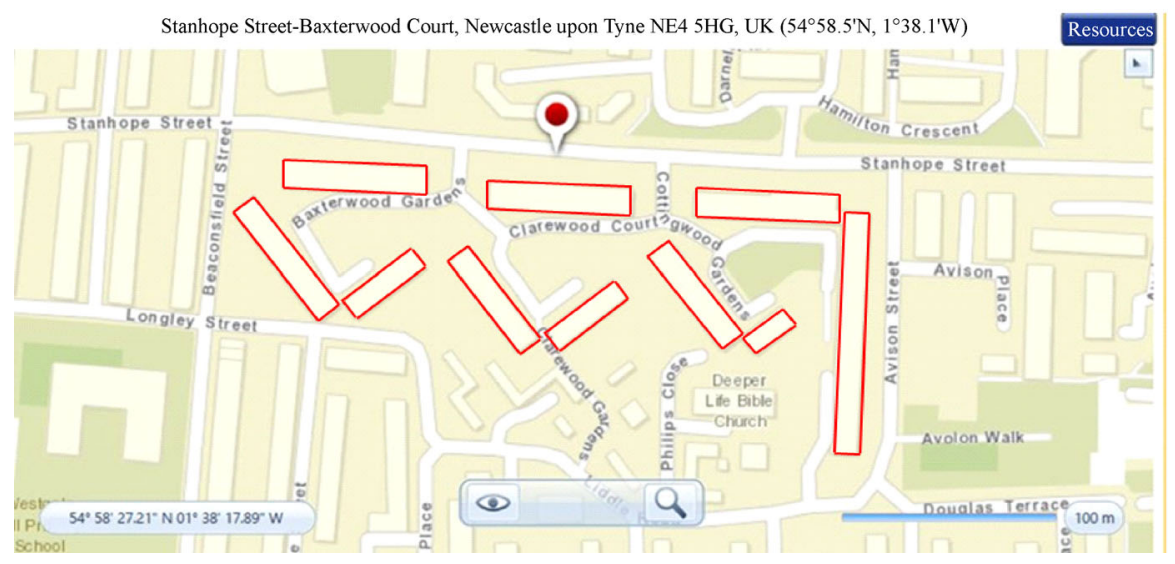

Fig. 1 Stanhope Street housing estate in Newcastle upon Tyne as presented in HOMER Pro. 
generation from renewable sources, to lower carbon dioxide emission, to reduce electricity purchase from the national grid, and to generate profit from selling the excess of energy generated on-site to the national grid.

As the housing estate is in a densely populated area, it would be unlikely to obtain a planning permission for deployment of a biomass plant near the site. The estate is in the significant distance from the coast or a river; thus, offshore wind turbines as well as hydropower were excluded from further analysis. However, well-established solar PV and onshore wind technologies were considered. It was assumed that there was a potential to install rooftop solar PV panels with a total capacity of $300 \mathrm{~kW}$ and 30 rooftop wind turbines with a capacity of $1 \mathrm{~kW}$. It was proposed to install the solar panels with a total capacity of $300 \mathrm{~kW}$ on 3 buildings facing north-south. The length and the width of the buildings was assessed during the site visit and it was as follow: each building was $60 \mathrm{~m}$ long and $10 \mathrm{~m}$ wide, giving a total roof area of $600 \mathrm{~m}^{2}$. It was assumed that 200 of $500 \mathrm{~W}$ solar panels with a size of $1.956 \mathrm{~m}$ by $1.31 \mathrm{~m}$, a $20 \%$ efficiency, and the surface area of $2.56 \mathrm{~m}^{2}$ per panel will be used on each building occupying a total area of $512 \mathrm{~m}^{2}$. The remaining roof area would provide an access to the array and the existing piping that is located on the roof. Such arrangement would allow for 600 panels in total with a capacity of $300 \mathrm{~kW}$ to be mounted on 3 out of 10 buildings.

It was also proposed to install $301 \mathrm{~kW}$ roof mounted wind turbines that are $4 \mathrm{~m}$ high with a $3 \mathrm{~m}$ diameter on 7 buildings that did not face north-south. All the buildings were $10 \mathrm{~m}$ wide, each of which has a different length: $20 \mathrm{~m}, 25 \mathrm{~m}, 40 \mathrm{~m}, 45 \mathrm{~m}, 50 \mathrm{~m}, 65$, and $110 \mathrm{~m}$. The total roof area available for wind turbines was assessed as $3550 \mathrm{~m}^{2}$. It was proposed to install 2 wind turbines each on buildings that were $20 \mathrm{~m}$ and $25 \mathrm{~m}$ long; 4 wind turbines each on buildings that were $40 \mathrm{~m}, 45 \mathrm{~m}$, and $50 \mathrm{~m}$ long; 6 turbines on a building that was $65 \mathrm{~m}$ long, and 8 wind turbines on a building that was $110 \mathrm{~m}$ long.

The solar PV potential for the housing estate was assessed using the Observed Solar Global Horizontal Irradiance data from the Nasa Surface Meteorology and Solar Energy database [31] for the period of 22 years: between July 1983 and June 2005. The annual profile of daily irradiation and the average solar irradiance was created in the HOMER Pro software.

The wind potential for the housing estate was also examined with the use of the HOMER Pro software. The observed data on wind speed obtained from the NASA Surface Meteorology and Solar Energy database [31] was uploaded to generate the wind profile and average wind speed.

The NASA Surface Meteorology and Solar Energy database forms part of a renewable energy resource databases sponsored by NASA's Applied Sciences Program in the Science Mission Directorate. The Surface Meteorology and Solar Energy (SSE) database data sets are formulated from various NASA and National Oceanic and Atmospheric Administration (NOAA) satellite observational programs. This database is embedded in the HOMER Pro software where the location specific data, based on GPS coordinates, are imported such as solar PV potential and wind potential data and used for the analysis [16,32-33].

\subsection{Proposed models}

Fourteen designs of energy systems were proposed (Table 1). It was assumed that all the models were connected to the national grid. Model 1 was designed to replicate a conventional energy system which was assumed to be in place on the housing estate under investigation and it did not consist of a CHP unit. Model 2 was equipped with a CHP unit, but it did not consist of renewable energy technologies and was designed as a control. Models 3 to 14 were coupled with CHP units and various configurations of solar PV and onshore wind technologies in various configurations to determine the most optimal combination. Models 3 to 8 were designed with CHP units in place and unrestricted size of solar PV and onshore wind to meet the target of $30 \%$ electricity generation from renewable sources. Models 9 to 14 had CHP units in place and limited renewable components with $300 \mathrm{~kW}$ for solar PV panels and $30 \mathrm{~kW}$ for onshore wind.

The size of the components included in the proposed models was designed to serve the assumed electrical and thermal loads of the housing estate.

Table 1 Proposed models with respect to the design components and the renewable energy technologies

\begin{tabular}{|c|c|c|c|c|c|c|c|c|c|c|c|c|c|c|}
\hline \multirow{3}{*}{$\begin{array}{l}\text { Model } \\
\text { components }\end{array}$} & \multicolumn{14}{|c|}{$\begin{array}{c}\text { Capacity of renewable energy technologies } \\
\text { Model number }\end{array}$} \\
\hline & \multicolumn{8}{|c|}{ Unrestricted } & \multicolumn{6}{|c|}{ Restricted } \\
\hline & 1 & 2 & 3 & 4 & 5 & 6 & 7 & 8 & 9 & 10 & 11 & 12 & 13 & 14 \\
\hline National grid & $\sqrt{ }$ & $\sqrt{ }$ & $\sqrt{ }$ & $\sqrt{ }$ & $\sqrt{ }$ & $\sqrt{ }$ & $\sqrt{ }$ & $\sqrt{ }$ & $\sqrt{ }$ & $\sqrt{ }$ & $\sqrt{ }$ & $\sqrt{ }$ & $\sqrt{ }$ & $\sqrt{ }$ \\
\hline CHP & - & $\sqrt{ }$ & $\sqrt{ }$ & $\sqrt{ }$ & $\sqrt{ }$ & $\sqrt{ }$ & $\sqrt{ }$ & $\sqrt{ }$ & $\sqrt{ }$ & $\sqrt{ }$ & $\sqrt{ }$ & $\sqrt{ }$ & $\sqrt{ }$ & $\sqrt{ }$ \\
\hline Solar PV & - & - & $\sqrt{ }$ & $\sqrt{ }$ & - & - & $\sqrt{ }$ & $\sqrt{ }$ & $\sqrt{ }$ & $\sqrt{ }$ & - & - & $\sqrt{ }$ & $\sqrt{ }$ \\
\hline Wind turbine & - & - & - & - & $\sqrt{ }$ & $\sqrt{ }$ & $\sqrt{ }$ & $\sqrt{ }$ & - & - & $\sqrt{ }$ & $\sqrt{ }$ & $\sqrt{ }$ & $\sqrt{ }$ \\
\hline Battery storage & - & - & - & $\sqrt{ }$ & - & $\sqrt{ }$ & - & $\sqrt{ }$ & - & $\sqrt{ }$ & - & $\sqrt{ }$ & - & $\sqrt{ }$ \\
\hline
\end{tabular}


In the design format without CHP, grid connection was assumed to meet the electrical load. In CHP included designs, grid connection was assumed to meet the shortfall of electricity demand that cannot be met by the CHP and/or the hybrid renewable energy systems and to generate the income from selling the surplus of energy produced by the system. The annual grid sale capacity was kept at the highest possible level to maximise the profit from selling electricity excess generated. The annual grid purchase capacity was kept at the value corresponding to the electric peak load $(575 \mathrm{~kW}), 20 \%$ below the peak load $(460 \mathrm{~kW})$, and $22 \%$ above the peak load $(700 \mathrm{~kW})$ to avoid demand charges or keep them to minimum.

A natural gas fired reciprocating CHP unit was assumed to meet the electrical and thermal baseloads of the housing estate and that it would minimise the energy purchase from the grid. To maximise the economic and environmental benefits from having CHP on-site, its minimum running annual operational time was to exceed $4500 \mathrm{~h}$. In the design without renewable energy technologies, a CHP unit was set up to serve the average electrical load. The CHP capacity was set up to allow for flexibility in performance.

In the CHP models, the capacity of the boiler was kept unlimited to meet the thermal demand above the thermal production of the CHP unit. In a model without CHP, the thermal demand was assumed to be served entirely by a natural gas fired boiler; the capacity of the boiler was also left as unlimited to meet the thermal load of the estate (no allowance for the peak load was made). The assumed efficiency of the boiler was $85 \%$.

Generic flat plate PV panels with a rated capacity of 1 $\mathrm{kW}$ and connected to DC electric bus were used in the design. A generic wind turbine with a rated capacity of 1 $\mathrm{kW}$ and connected to $\mathrm{AC}$ electric bus was used in the design.

A battery storage unit, when included in the design, was assumed to address the fluctuating nature of renewable energy and to store the surplus of electricity generated by the system. Generic $1 \mathrm{~kW}$ lithium-ion batteries were used, when applicable. The size of this component was optimised by the HOMER Optimiser ${ }^{\mathrm{TM}}$ tool to suit the output of the renewable energy technologies.

The size of the AC-DC converter, when used, was optimised by the HOMER Optimiser ${ }^{\mathrm{TM}}$ tool to suit the size of the solar PV component.

To aid model comparison, it was assumed that the heat recovery ratio of a CHP unit was $60 \%$; the solar PV derating factor was $80 \%$ and the capacity factor was $10.5 \%$; the capacity factor of wind turbines was $16.4 \%$; the efficiency of converters was $95 \%$ with a capacity factor of $14.6 \%$; and the roundtrip efficiency (DC to storage to DC) of battery storage units was $90 \%$.

The overall feasibility of the proposed models is influenced by the investment cost and the technical performance of the components. To aid model comparison the following average prices of the components and their technical performance were assumed: $\$ 105000$ for a natural gas fired reciprocating CHP unit with a heat recovery ratio of $60 \%$, a rated power efficiency of $37.9 \%$ and a lifetime of $20000 \mathrm{~h} ; \$ 1250$ for a $500 \mathrm{~W}$ solar panel with a derating factor of $80 \%$, a capacity factor of $10.5 \%$, and a lifetime of 25 years; $\$ 7000$ for a $1 \mathrm{~kW}$ wind turbine with a capacity factor of $16.4 \%$ and a lifetime of 20 years; $\$ 300$ for a converter with an efficiency of $95 \%$, a capacity factor of $14.6 \%$, and a lifetime of 15 years; and $\$ 550$ for a 1 $\mathrm{kWh}$ lithium-ion battery with a roundtrip efficiency (DC to storage to DC) of battery storage units of $90 \%$ and a lifetime of 15 years. It was also assumed that the average power efficiency of the national grid was $91.5 \%$ with $8.5 \%$ distribution and transmission losses. The interest rate applied was $5.88 \%$ and the lifetime of the project was 25 years.

The architecture of HOMER Pro designs representing Models 1 to 8 with the components indicated in Table 1 is presented in Fig. 2. The schematic representation of Models 9 to 14 is identical with Models 3 to 8 respectively. Two sets of models differ with respect to the size of the renewable energy components that is not graphically represented in HOMER Pro software.

Details of the resolved models indicating fixed and values calculated using HOMER Optimiser ${ }^{\mathrm{TM}}$ is shown in Table 2. This includes the energy ratings of the boiler, CHP, solar PV, converter, wind turbine and batteries.

\section{Results}

The solutions that were generated by the software for each of the proposed models contained the details on the system design, capacities of the components, costs, fuel consumption, renewable fraction and carbon dioxide emissions. This has been organized in terms of technical, economic and environmental performance.

\subsection{Technical performance}

The technical feasibility of the proposed models was assessed with respect to the potential for solar and wind energy sources, and the capacity of these renewable energy technologies.

The annual average solar radiation for the housing estate located at Stanhope Street was $2.61 \mathrm{kWh} /\left(\mathrm{m}^{2} \cdot \mathrm{d}\right)$. The highest daily radiation was observed in summer months with $4.73 \mathrm{kWh} /\left(\mathrm{m}^{2} \cdot \mathrm{d}\right)$ in June, $4.67 \mathrm{kWh} /\left(\mathrm{m}^{2} \cdot \mathrm{d}\right)$ in May, and $4.62 \mathrm{kWh} /\left(\mathrm{m}^{2} \cdot \mathrm{d}\right)$ in July. The lowest daily radiation was observed in winter months with $0.47 \mathrm{kWh} /\left(\mathrm{m}^{2} \cdot \mathrm{d}\right)$ in December, $0.63 \mathrm{kWh} /\left(\mathrm{m}^{2} \cdot \mathrm{d}\right)$ in January, and $0.77 \mathrm{kWh} /\left(\mathrm{m}^{2} \cdot \mathrm{d}\right)$ in November. The annual profile of the daily irradiation generated in the software was presented in Fig. 3.

The annual average wind speed for the housing estate was $6.19 \mathrm{~m} / \mathrm{s}$. The highest wind speed was observed in 


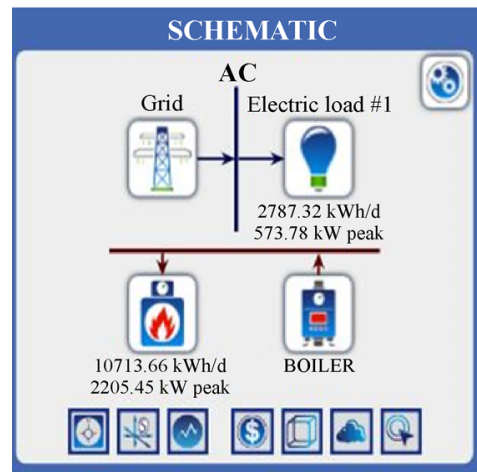

(a)

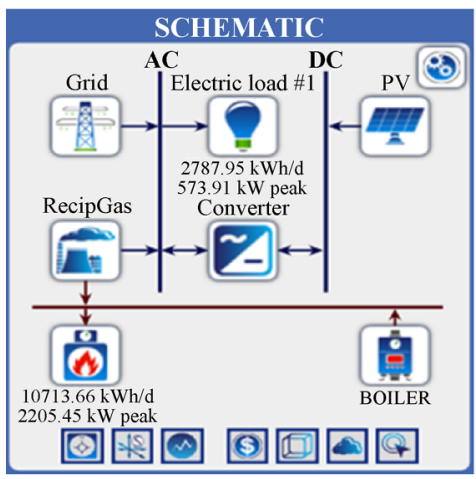

(c)
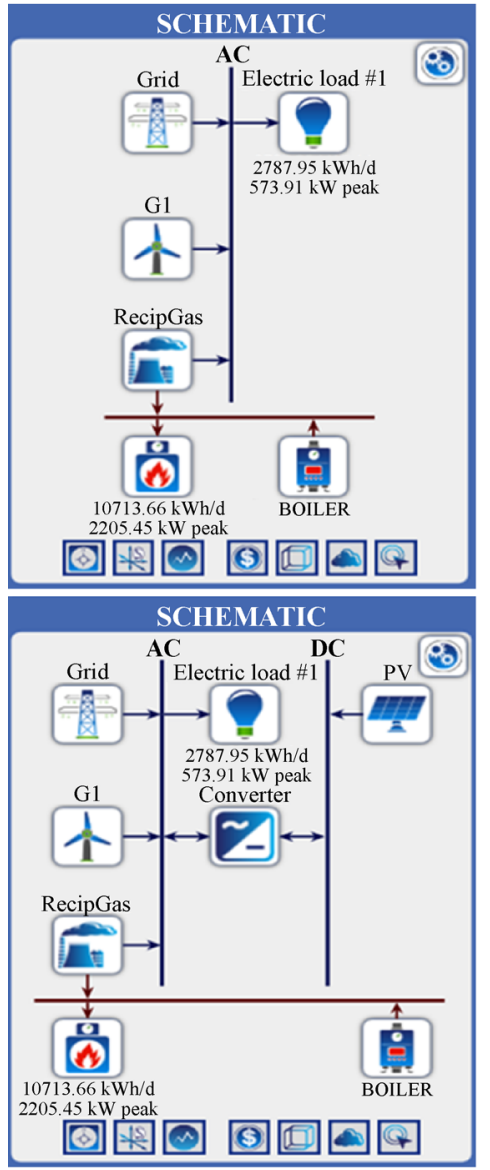

(e)

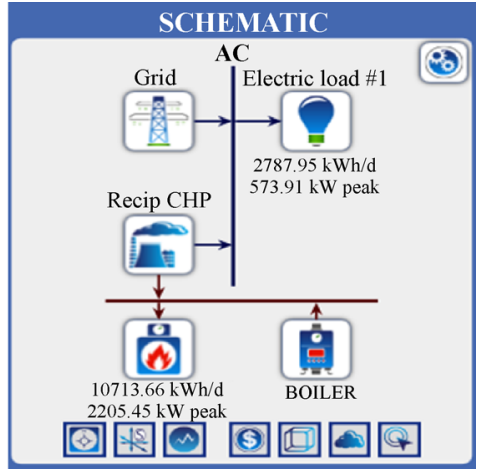

(b)

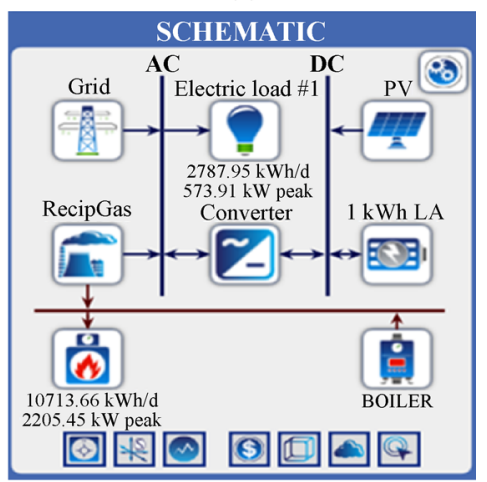

(d)
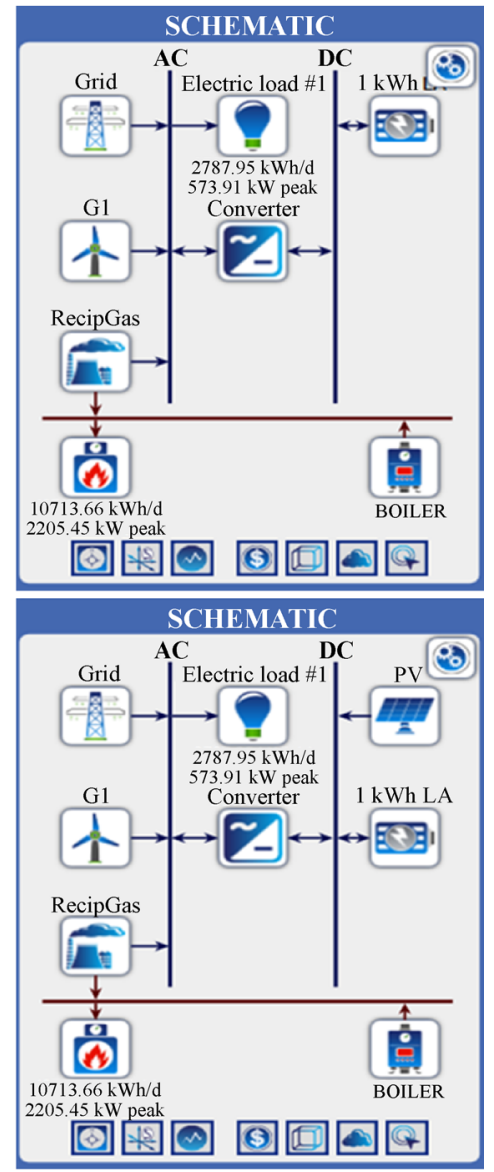

(f)

Fig. 2 Architecture of HOMER Pro designs representing Models 1 to 8 with the components indicated in Table 1. (a) Model 1; (b) Model 2; (c) Models 3 and 9; (d) Models 4 and 10; (e) Models 5 and 11; (f) Models 6 and 12. 
Table 2 Details of the resolved models indicating fixed and calculated values

\begin{tabular}{|c|c|c|c|c|c|c|c|c|c|c|c|c|c|c|}
\hline \multirow{3}{*}{ Components } & \multicolumn{14}{|c|}{ Model details } \\
\hline & \multicolumn{8}{|c|}{ Unrestricted } & \multicolumn{6}{|c|}{ Restricted } \\
\hline & 1 & 2 & 3 & 4 & 5 & 6 & 7 & 8 & 9 & 10 & 11 & 12 & 13 & 14 \\
\hline$\overline{\text { Boiler } / \mathrm{kW}}$ & $2205^{\text {(a) }}$ & $2058^{(\mathrm{a})}$ & $2058^{(\mathrm{a})}$ & $2058^{(\mathrm{a})}$ & $2205^{(\mathrm{a})}$ & $2205^{(\mathrm{a})}$ & $2058^{(\mathrm{a})}$ & $2058^{(\mathrm{a})}$ & $2058^{(\mathrm{a})}$ & $2058^{(\mathrm{a})}$ & $2058^{(\mathrm{a})}$ & $2058^{(a)}$ & $2058^{(\mathrm{a})}$ & $2058^{(\mathrm{a})}$ \\
\hline $\mathrm{CHP} / \mathrm{kW}$ & - & $150^{(\mathrm{b})}$ & $150^{(\mathrm{b})}$ & $150^{(\mathrm{b})}$ & $150^{(\mathrm{b})}$ & $150^{(\mathrm{b})}$ & $150^{(\mathrm{b})}$ & $150^{(\mathrm{b})}$ & $150^{(\mathrm{b})}$ & $150^{(\mathrm{b})}$ & $150^{(\mathrm{b})}$ & $150^{(\mathrm{b})}$ & $150^{(\mathrm{b})}$ & $150^{(\mathrm{b})}$ \\
\hline Solar PV/kW & - & - & $2597^{(\mathrm{a})}$ & $2593^{(\mathrm{a})}$ & - & - & $2575^{\text {(a) }}$ & $2715^{(\mathrm{a})}$ & $300^{(\mathrm{b})}$ & $300^{(\mathrm{b})}$ & - & - & $300^{(\mathrm{b})}$ & $300^{(\mathrm{b})}$ \\
\hline Converter $/ \mathrm{kW}$ & - & - & $1801^{(a)}$ & $1832^{\text {(a) }}$ & - & $266^{(\mathrm{a})}$ & $1855^{(\mathrm{a})}$ & $1508^{(a)}$ & $144^{(\mathrm{a})}$ & $148^{(\mathrm{a})}$ & - & $4.48^{(\mathrm{a})}$ & $144^{(\mathrm{a})}$ & $148^{(\mathrm{a})}$ \\
\hline Wind turbine $/ \mathrm{kW}$ & - & - & - & - & $1496^{(a)}$ & $1328^{(a)}$ & $9^{(a)}$ & $15^{\text {(a) }}$ & - & - & $30^{(\mathrm{b})}$ & $30^{(\mathrm{b})}$ & $30^{(\mathrm{b})}$ & $30^{(\mathrm{b})}$ \\
\hline Batteries $/ \mathrm{kWh}$ & - & - & - & $37^{(\mathrm{a})}$ & - & $129^{(a)}$ & - & $5^{(\mathrm{a})}$ & - & $18^{(\mathrm{a})}$ & - & $18^{(\mathrm{a})}$ & - & $18^{(\mathrm{a})}$ \\
\hline
\end{tabular}

Notes: (a)—_fixed value; (b)— value calculated with HOMER Optimiser ${ }^{\mathrm{TM}}$.

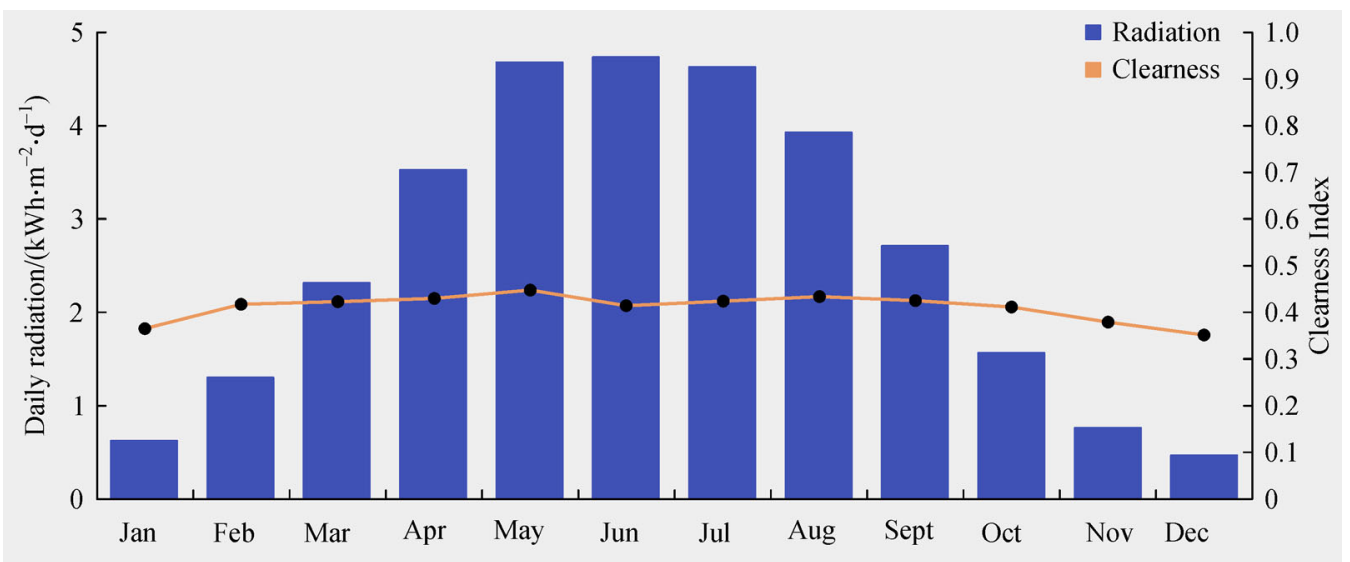

Fig. 3 Annual profile of daily average radiation with the Clearness Index.

winter months with the highest value of $7.370 \mathrm{~m} / \mathrm{s}$ in January and $7.080 \mathrm{~m} / \mathrm{s}$ in December. The lowest average wind speed was observed in July, $4.940 \mathrm{~m} / \mathrm{s}$. The monthly average wind speed was presented in Fig. 4.

The capacities of renewable energy technologies optimised by the HOMER software for models with unrestricted size of the renewable components were presented in Table 3 with respect to the architecture of the models.

The capacity of solar PV for unrestricted models varied between $2575 \mathrm{~kW}$ for Model 7 and $2715 \mathrm{~kW}$ for Model 8 . The wind capacity varied between $9 \mathrm{~kW}$ for Model 7 and $1496 \mathrm{~kW}$ for Model 5.

In models with one type of renewable technology, the size of solar component (Models 3 and 4) was significantly higher than that of onshore wind (Models 5 and 6). The same trend was observed in Models 7 and 8 that consist of both types of renewable technologies. The size of solar component significantly exceeded the wind capacity and the difference was more pronounced.

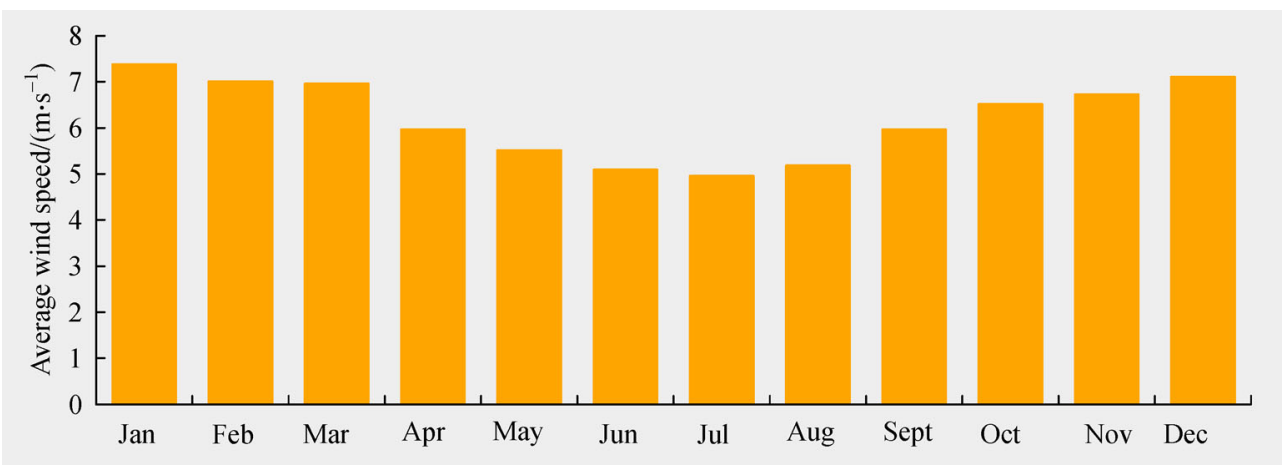

Fig. 4 Monthly average wind speed. 
Table 3 Models with unrestricted renewable energy technologies; the size of renewable energy components in proposed models with respect to the models' architecture

\begin{tabular}{lccc}
\hline Model number & Model architecture & Size of renewable energy components/kW & Wind \\
\hline 1 & No renewables (NO CHP) & PV & - \\
2 & No renewables (CHP) & - & - \\
3 & PV (CHP) & 2597 & - \\
4 & PV + battery (CHP) & 2593 & 1496 \\
5 & Wind (CHP) & - & 1328 \\
6 & Wind + battery (CHP) & 9 \\
7 & PV + wind (CHP) & 2575 & 15 \\
\hline
\end{tabular}

The capacities of renewable energy technologies in models with restricted size of renewable energy technologies were fixed: $300 \mathrm{~kW}$ for solar PV and $30 \mathrm{~kW}$ for onshore wind.

\subsection{Economic performance}

The economic feasibility of the proposed models with unrestricted renewable energy technologies was analyzed and compared with respect to the net present cost (NPC), the cost of energy (COE), the operating cost (OC), and the investment cost (IC). The costs associated with the models with unrestricted renewable energy technologies are provided in Table 4 and Fig. 5.

The net present cost for the proposed models with unrestricted renewables varied between $\$ 2.93$ million and $\$ 15.3$ million. Models 1 and 2, with no renewable technologies, had the lowest NPC (\$2.93 million and $\$ 3.62$ million, respectively). The highest NPC was observed for Models 5 and 6 with onshore wind but no solar PV (\$15.3 million and \$13.8 million, respectively). The NPC for the rest of the models oscillated between $\$ 9.70$ million and \$10.0 million (Model 3 and Model 8, respectively).

The cost of energy for the proposed models with unrestricted renewables varied between $\$ 0.100$ (Model 1) and $\$ 0.379$ (Model 6). The cost of energy was the lowest in Models 1 and 2 with no renewable technologies and the highest in models that contain onshore wind but no solar component (Models 5 and 6). For the remaining models, the cost of energy varied between $\$ 0.172$ (Model 3) and $\$ 0.323$ (Model 5).

The operating cost for the proposed models with unrestricted renewables was the lowest for Models 3 and 8 (\$188535 and $\$ 188721$, respectively) and the highest for Model 5 (\$357981). For other models, the operating cost varied between $\$ 189563$ (Model 4) and \$316609 (Model $6)$. The operating cost was the highest for models with onshore wind component.

The investment cost for the proposed models with unrestricted renewables was the lowest for Model $1(\$ 0)$ and then for Model 2 (\$225000). The highest investment cost would be required for Model 5 (\$10.7 million) and Model 6 (\$9.67 million) that consist onshore wind component. The investment cost for the remaining models oscillated between \$7.26 million (Models 3) and \$7.57 million (Model 8).

The proposed models with restricted renewable energy technologies were also compared with respect to the cost variables, as presented in Table 5 and Fig. 6.

The net present cost for the proposed models with fixed renewables was the lowest for Models 11 and 12 that

Table 4 Models with unrestricted renewable energy technologies: Economic variables

\begin{tabular}{|c|c|c|c|c|c|}
\hline \multirow{2}{*}{ Model } & \multirow{2}{*}{ Model architecture } & \multicolumn{4}{|c|}{ Costs $/ \$$} \\
\hline & & NPC & COE & $\mathrm{OC}$ & IC \\
\hline$\overline{1}$ & No renewables (NO CHP) & $2.93 \mathrm{M}$ & 0.100 & 226812 & 0.00 \\
\hline 2 & No renewables (CHP) & $3.62 \mathrm{M}$ & 0.103 & 262391 & $0.225 \mathrm{M}$ \\
\hline 3 & PV (CHP) & $9.70 \mathrm{M}$ & 0.172 & 188535 & $7.26 \mathrm{M}$ \\
\hline 4 & $\mathrm{PV}+$ battery $(\mathrm{CHP})$ & $9.73 \mathrm{M}$ & 0.173 & 189563 & $7.28 \mathrm{M}$ \\
\hline 5 & Wind (CHP) & $15.3 \mathrm{M}$ & 0.323 & 357981 & $10.7 \mathrm{M}$ \\
\hline 6 & Wind + battery (CHP) & $13.8 \mathrm{M}$ & 0.379 & 316609 & $9.67 \mathrm{M}$ \\
\hline 7 & $\mathrm{PV}+$ wind $(\mathrm{CHP})$ & $9.73 \mathrm{M}$ & 0.173 & 189725 & $7.28 \mathrm{M}$ \\
\hline 8 & $\mathrm{PV}+$ wind + battery $(\mathrm{CHP})$ & $10.0 \mathrm{M}$ & 0.179 & 188721 & $7.57 \mathrm{M}$ \\
\hline
\end{tabular}




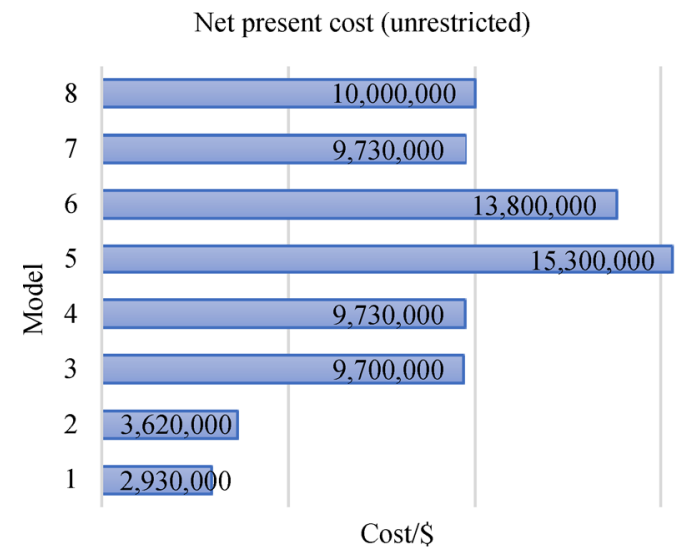

(a)

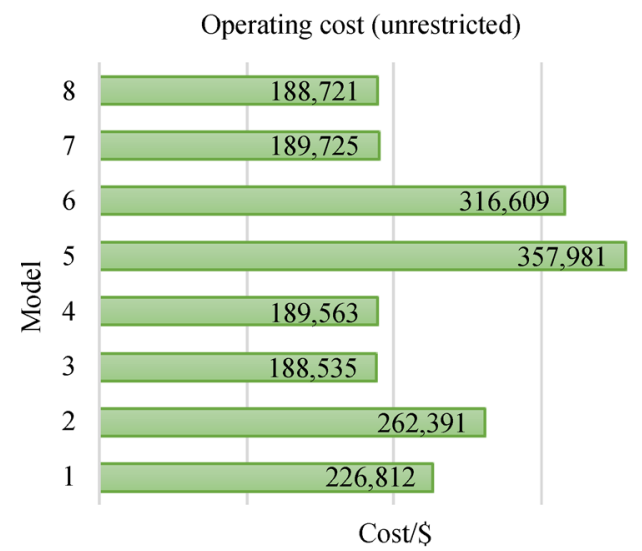

(c)

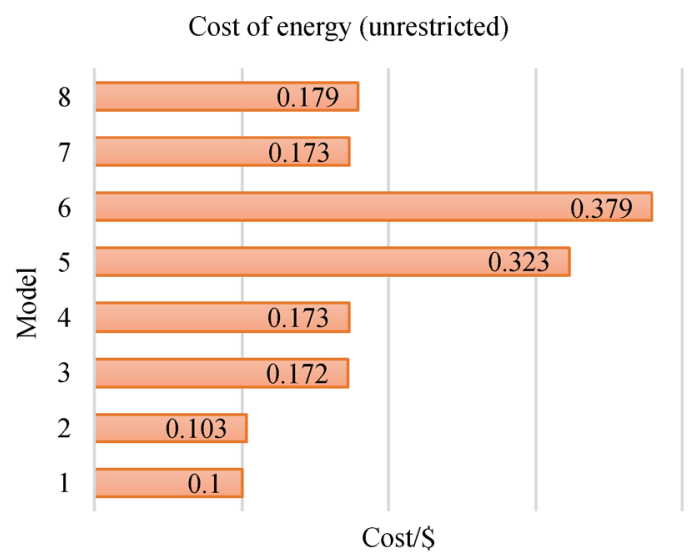

(b)

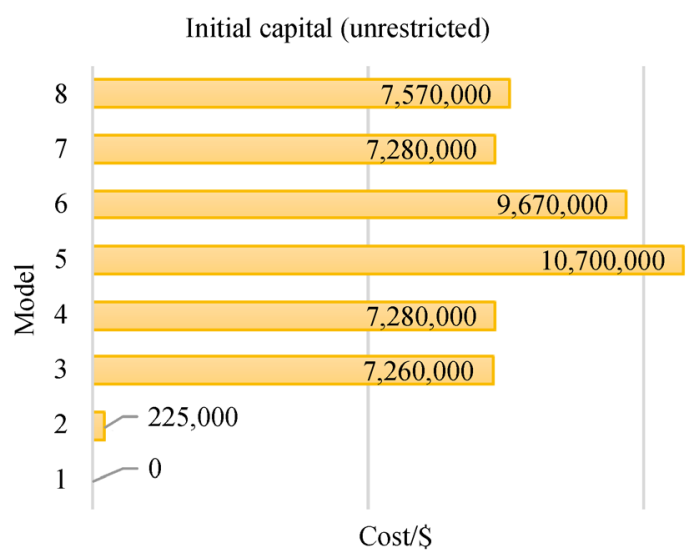

(d)

Fig. 5 Economic parameters for models with unrestricted renewable energy technologies comparing.

(a) Net present cost; (b) cost of energy; (c) operating cost; (d) initial capital.

Table 5 Models with restricted renewable energy technologies: economic variables

\begin{tabular}{lccccc}
\hline \multirow{2}{*}{ Model number } & $\begin{array}{c}\text { Model architecture } \\
\text { (CHP) }\end{array}$ & NPC & COE & OC & Costs/\$ \\
\cline { 3 - 6 } & PV & $4.30 \mathrm{M}$ & 0.123 & 253639 & $1.02 \mathrm{M}$ \\
10 & PV + battery & $4.31 \mathrm{M}$ & 0.124 & 253991 & $1.03 \mathrm{M}$ \\
11 & Wind & $3.85 \mathrm{M}$ & 0.114 & 263914 & $0.435 \mathrm{M}$ \\
12 & Wind + battery & $3.86 \mathrm{M}$ & 0.115 & 264394 & $0.446 \mathrm{M}$ \\
13 & PV + wind & $4.53 \mathrm{M}$ & 0.132 & 255323 & $1.23 \mathrm{M}$ \\
14 & PV + wind + battery & $4.54 \mathrm{M}$ & 0.132 & 255675 & $1.24 \mathrm{M}$ \\
\hline
\end{tabular}

consist onshore wind (\$3.85 million and \$3.86 million, respectively) and the highest for Models 13 and 14 that combine both types of renewable energy technologies (\$4.53 million and \$4.54 million, respectively). The NPC for models with solar component oscillated between $\$ 4.30$ million and $\$ 4.54$ million (Models 9 and 14, respectively).

The cost of energy for the models with fixed size of renewables varied between $\$ 0.114$ (Model 11) and $\$ 0.132$ (Models 13 and 14). The cost of energy was the lowest for models with onshore wind and the highest for models with both types of renewable technologies. For models with solar component, the cost of energy was $\$ 0.123$ (Model 9) and \$0.124 (Model 10).

The operating cost for the models with restricted size of renewables was the lowest for Model 9 (\$253639) and the highest for Model 12 (\$264394). Models with wind component had the highest operating cost, followed by models with both types of renewable technologies. The operating cost was the lowest for models with solar PV. The model differences in this parameter is again marginal. 
The initial capital for the model with fixed size of renewables was the lowest for Models 11 and 12 with onshore wind ( $\$ 435000$ and $\$ 446245$, respectively). The initial capital was the highest for Models 13 and 14 that consist both types of renewable technologies $(\$ 1.23$ million and $\$ 1.24$ million, respectively). The investment cost for Models 9 and 10 with solar PV was $\$ 1.02$ million (Model 9) and \$1.03 million (Model 10).

The proposed models were also compared with respect to the grid sales to investigate the potential of a model for generating a profit. The grid sales for models with unrestricted renewables were presented in Table 6 and Fig. 7.

The grid sales of Model 1, that does not contain CHP nor renewable energy technologies, was zero. The grid sales of

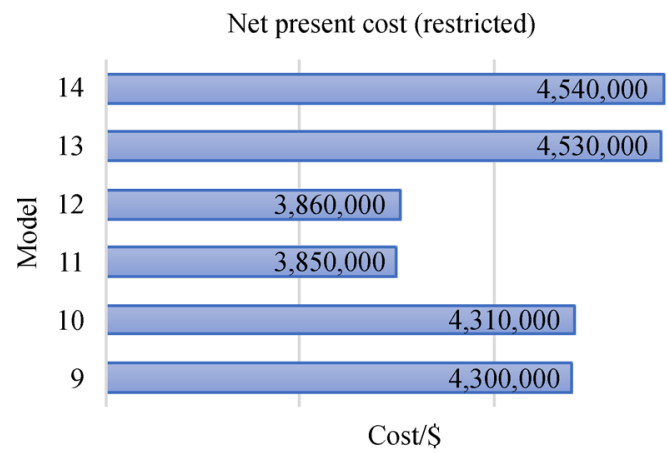

(a)

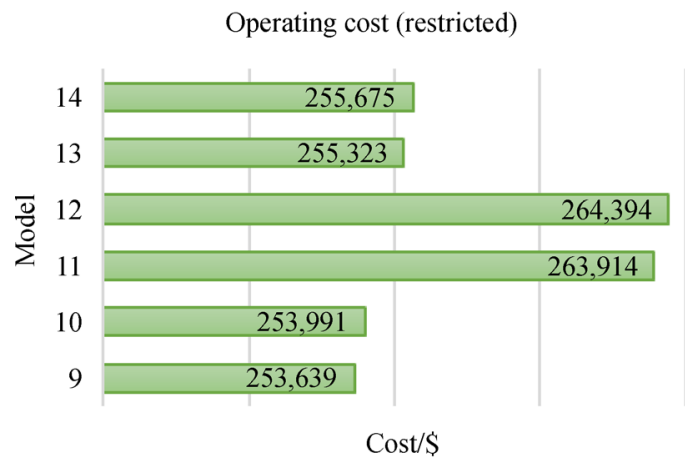

(c)
Model 2, with CHP but with no renewables, was the lowest of all the models with $24.8 \%$. The highest percentage of energy sold to the grid and exceeding $71 \%$ was seen in Models 3, 4, 7, and 8 that consist solar component only and in models with both types of renewable technologies in place. In the remaining models, the grid sales varied between 58.3\% (Model 6) and 68.6\% (Model 5). With exception of Model 6, where grid sales and power generation were significantly lower than in other models, the variation in energy sold to the grid between Models 3, $4,5,7$ and 8 is marginal (Fig. 6). Therefore, this parameter cannot be used to distinguish models. These models generated roughly the same amount of power and therefore has the same excesses that can be sold to the grid.

Grid sales were also compared for models with fixed size

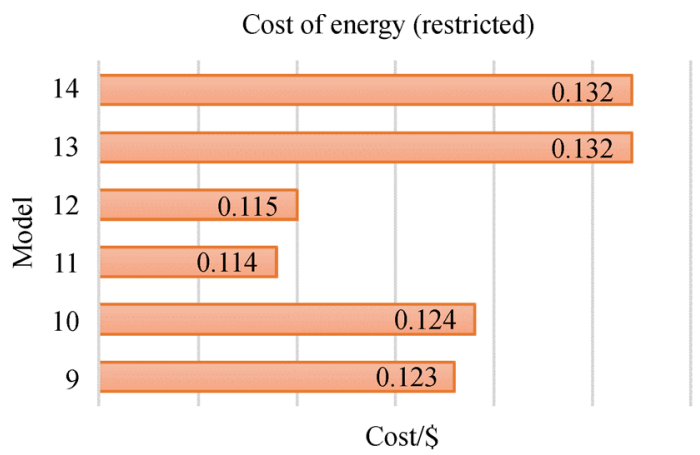

(b)

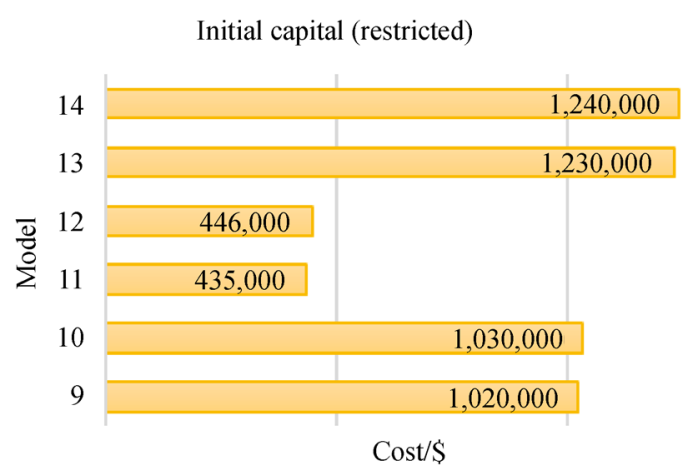

(d)

Fig. 6 Economic parameters for models with restricted renewable energy technologies comparing.

(a) Net present cost; (b) cost of energy; (c) operating cost; (d) initial capital.

Table 6 Models with unrestricted renewables: grid sales with respect to model architecture

\begin{tabular}{lcccc}
\hline Model number & Model architecture & $\begin{array}{c}\text { Energy sold to the } \\
\text { grid/kWh }\end{array}$ & $\begin{array}{c}\text { Total power } \\
\text { generated/kWh }\end{array}$ & $\begin{array}{c}\text { Percentage of total } \\
\text { power/\% }\end{array}$ \\
\hline 1 & No renewables (NO CHP) & 0.0 & 1017600 & 0.0 \\
2 & No renewables (CHP) & 335468 & 1353068 & 24.8 \\
3 & PV (CHP) & 2526229 & 3543829 & 71.3 \\
4 & PV + battery (CHP) & 2527966 & 3545566 & 71.3 \\
5 & Wind (CHP) & 2222502 & 3240102 & 68.6 \\
6 & Wind + battery (CHP) & 1425354 & 2442954 & 58.3 \\
7 & PV + wind (CHP) & 2527647 & 3545247 & 71.3 \\
\hline
\end{tabular}


of renewable components (Table 7 and Fig. 8). The grid sales in models with fixed size of renewable components varied between $26.4 \%$ and $36.4 \%$. The lowest grid sales were observed in Models 11 and 12 with onshore wind and the highest in Models 13 and 14 that combine both types of renewable technologies. In models with solar PV, the grid sales varied between $35.0 \%$ (Model 9) and 35.1\% (Model 10).

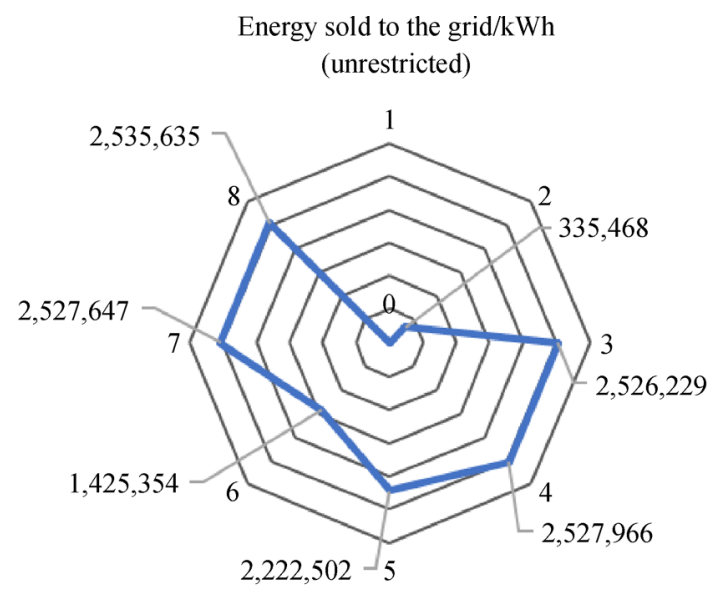

(a)

Total power generated/kWh (unrestricted)

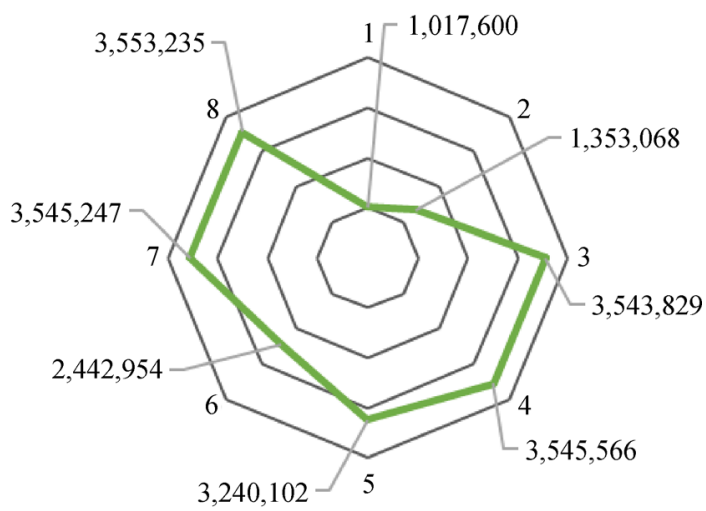

(b)

Fig. 7 Grid sales comparison for models with unrestricted renewables comparing.

(a) Energy sold to the grid; (b) total power generated.

\subsection{Environmental performance}

Optimized models with unrestricted renewable energy technologies were compared with respect to renewable fraction and carbon dioxide emissions (Table 8 and Fig. 9).

The renewable fraction in Models 1 and 2 was zero. For other models, renewable fraction varied between $30.0 \%$ (Model 3, 4, and 6) and 30.2\% (Model 6).

Carbon dioxide emission was the highest in models with no renewable component with $1452114 \mathrm{~kg} / \mathrm{a}$ in Model 1 and $1358683 \mathrm{~kg} / \mathrm{a}$ in Model 2. The lowest emission level was observed in models with onshore wind with 1198731 $\mathrm{kg} / \mathrm{a}$ in Model 6 and $1259105 \mathrm{~kg} / \mathrm{a}$ in Model 5. The emissions in the remaining models varied between $1326015 \mathrm{~kg} / \mathrm{a}$ (Model 8) and $1329110 \mathrm{~kg} / \mathrm{a}$ (Model 4). It is evident that conventional systems, such as Model 1, emits higher levels of carbon dioxide. With renewable components in place, the carbon dioxide emissions can be reduced by $8.5 \%$ (Model 3) to 17.4\% (Model 6).

Environmental performance was also examined in models with restricted size of renewable energy technologies (Table 9 and Fig. 10).

The renewable fraction for models with restricted renewables was the lowest in Models 11 and 12 that consisted the onshore wind technology $(0.80 \%)$, and the highest in models consisting both types of renewables (5.10\% in Model 14 and 5.00\% in Model 13). The renewable fraction in models with solar component was 4.30\% in Model 9 and $4.10 \%$ in Model 10.

Carbon dioxide emissions were the lowest in models combining solar PV and onshore wind $(1337592 \mathrm{~kg} / \mathrm{a}$ in Model 13 and $1337616 \mathrm{~kg} / \mathrm{a}$ in Model 14). Models 11 and 12 that consisted onshore wind had the highest level of emissions with $1350055 \mathrm{~kg} / \mathrm{a}$. Emission levels in the models with solar PV varied between $1344185 \mathrm{~kg} / \mathrm{a}$ (Model 9) and $1344616 \mathrm{~kg} / \mathrm{a}$ (Model 10). With fixed size of renewable components in place, the carbon dioxide emission can be reduced from $7 \%$ to $8 \%$ (when compared to model 1). However, the difference between the models is not significant.

\subsection{Best overall performance}

The designs with best performance in each of the economic and environmental category were identified and an overall

Table 7 Models with restricted renewables: grid sales with respect to model architecture

\begin{tabular}{lcccc}
\hline Model number & $\begin{array}{c}\text { Model architecture } \\
(\mathrm{CHP})\end{array}$ & $\begin{array}{c}\text { Energy sold to } \\
\text { the grid/kWh }\end{array}$ & $\begin{array}{c}\text { Total power } \\
\text { generated/kWh }\end{array}$ & $\begin{array}{c}\text { Percentage of } \\
\text { total power/\% }\end{array}$ \\
\hline 9 & PV & 547560 & 1565160 & 35.0 \\
10 & PV + battery & 550021 & 1567621 & 35.1 \\
11 & Wind & 364904 & 1382504 & 26.4 \\
12 & Wind + battery & 364904 & 1382504 & 26.4 \\
13 & PV + wind & 580222 & 1597822 & 36.3 \\
14 & PV + wind + battery & 582689 & 1600289 & 36.4 \\
\hline
\end{tabular}




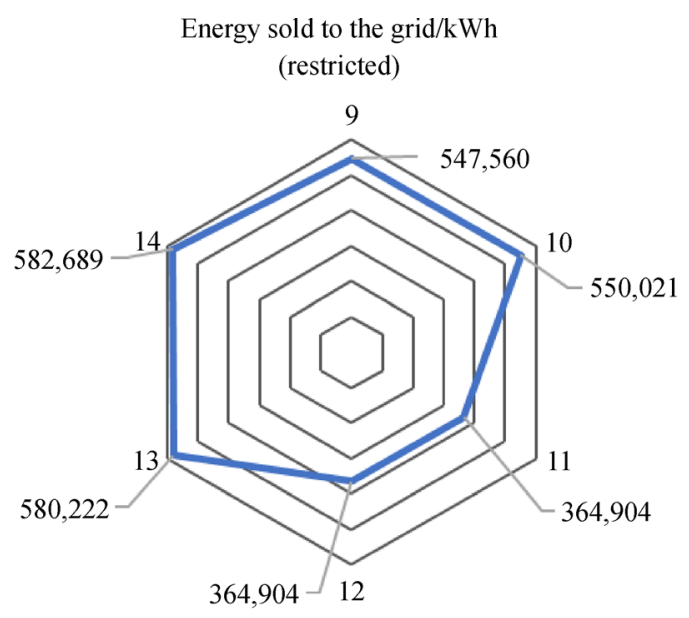

(a)

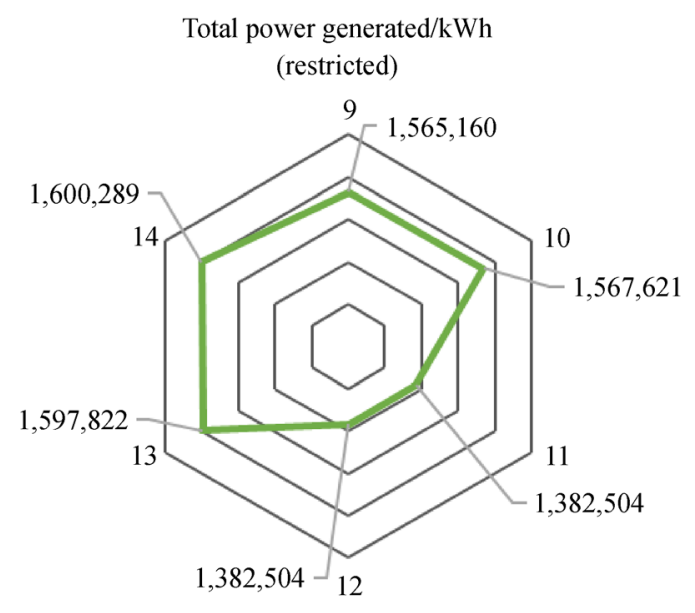

(b)

Fig. 8 Comparison of grid sales for models with restricted renewables.

(a) Energy sold to the grid; (b) total power generated.

preferred model selected. Table 10 is derived from the data presented in Figs. 11, 12, and 13 and previously discussed in Sections 3.1, 3.2, and 3.3.

In models with unrestricted capacity of the renewable component, none of the models was performing the best in each category. Since Models 1 and 2 were used as controls, they were not included in the analysis of the unrestricted components. When analyzed from a strictly numerical perspective, Model 3 performed the best in the categories of net present cost, cost of energy, operating cost, and initial capital investment. Model 8 has the highest grid sales. There is no discernible difference between models from an environmental perspective. Therefore, any model can be chosen in this category. The overall preferred models in the unrestricted category can be any of Models 3 or 8 when all the performance categories are considered. The only models that were excluded are Models 5 and 6 . This is based on the high costs associated with these models, a marginally higher energy sold to the grid, and no real benefit in terms of $\mathrm{CO}_{2}$ emissions in comparison with the other models.

In models with restricted capacity of the renewable component, there was no model that performed optimally in each single category. Model 11 fared the best in the net present cost, cost of energy, and initial capital investment, yet this model yielded a lower amount of energy sold to the grid in comparison with other models. The operating cost of Model 9 was the lowest, while Model 14 had the highest grid sales. The renewable fraction of Model 14 was the highest. The models all had comparable values of $\mathrm{CO}_{2}$ emissions. Therefore, any model can be selected in this category. The overall preferred models in the restricted renewable category is Models 14 . Models 11 and 12 are eliminated based on the lower renewable fraction and gird sales, since they make use of wind energy only.

The aim of this paper is to identify a configuration that can assist with alleviating fuel poverty at the Stanhope Street housing estate. This configuration must be technically and economically feasible while meeting a reduced carbon target. The model that is proposed for implementation is Model 14. The rationale behind this selection is discussed in Section 4.

\section{Discussion}

\subsection{Technical feasibility}

The technical feasibility of the proposed designs was

Table 8 Models with unrestricted renewable energy technologies: renewable fraction and $\mathrm{CO}_{2}$ emissions

\begin{tabular}{lccc}
\hline Model number & Model architecture & Renewable fraction $/ \%$ & $\mathrm{CO}_{2} \mathrm{emissions} /\left(\mathrm{kg} \cdot \mathrm{a}^{-1}\right)$ \\
\hline 1 & No renewables (NO CHP) & 0.0 & 1452114 \\
2 & No renewables (CHP) & 0.0 & 1358683 \\
3 & PV (CHP) & 30.0 & 1329046 \\
4 & PV + battery (CHP) & 30.0 & 1329110 \\
5 & Wind (CHP) & 30.1 & 1259105 \\
6 & Wind + battery (CHP) & 30.0 & 1198731 \\
7 & PV + wind (CHP) & 30.1 & 1327473 \\
8 & PV + wind + battery (CHP) & 30.2 & 1326015 \\
\hline
\end{tabular}




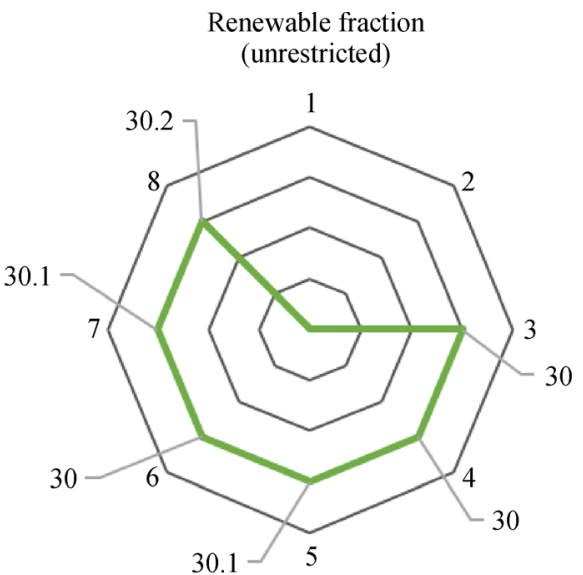

(a)

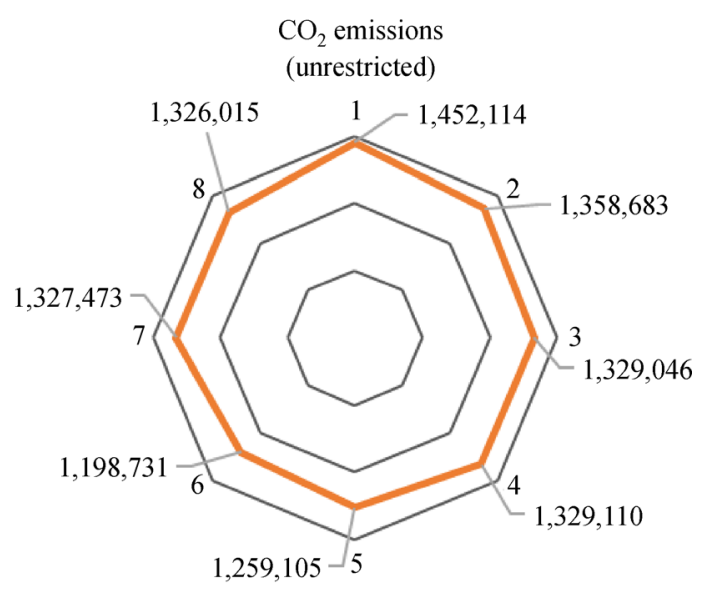

(b)

Fig. 9 Renewable fraction and carbon dioxide emissions for models with unrestricted renewable energy technologies.

(a) Renewable fraction; (b) $\mathrm{CO}_{2}$ emissions.

assessed with respect to the solar and wind potential, and the size of renewable energy components.

With the annual average solar irradiation measured for the housing estate of $2.61 \mathrm{kWh} /\left(\mathrm{m}^{2} \cdot \mathrm{d}\right)$ and the annual average wind speed of $6.19 \mathrm{~m} / \mathrm{s}$, the proposed renewable technologies are feasible in the given location.

In models with unrestricted renewable components, the optimised size of solar PV of $2575 \mathrm{~kW}$ to $2715 \mathrm{~kW}$ significantly exceeds the size that was predicted as technically feasible during the site survey i.e., $300 \mathrm{~kW}$. The roof area of the buildings facing north-south is not big enough to accommodate such extensive solar component. As the site is in densely populated area, on-the-ground solar farm would not be feasible. However, with further technological advancements, the generation capacity per square meter of solar panel could have potentially increased allowing larger capacity of solar PV components to be installed in locations where such capacity proves to be currently technically challenging. Considering this, Models 3, 4, 7, and 8 is excluded as possible solutions to the fuel poverty problem at the Stanhope Street estate.

The size of wind component in proposed models with unrestricted renewable energy technologies varied between $9 \mathrm{~kW}$ and $1496 \mathrm{~kW}$. In models combining both types of renewables, the wind component of $9 \mathrm{~kW}$ and $15 \mathrm{~kW}$ is below the maximum size assessed as feasible. The wind turbines would have to be installed on the roofs as there is not enough space between the buildings to accommodate wind turbines and allow for adequate exposure to wind.

The size of wind component in models with a single type of renewable energy technology was $1328 \mathrm{~kW}$ and 1496 $\mathrm{kW}$. The deployment of wind turbine of that size would not be feasible, and it would not be permitted by the authorities due to several reasons, further excluding Models 5 and 6 as possible solutions. As the buildings on the housing estate are four storeys, the hub of a potential wind turbines would have to be at significant height causing hazard to aircrafts.

Health and safety issues related to keeping safe distance from the blades, as well significant noise and shadow flicker affecting the wellbeing of the tenants would apply to both larger and smaller wind turbines.

It could also be expected that tenants and those living nearby the estate would complain about the visual aspect of wind turbines. Achieving planning permission would also be challenging for large wind turbines, if not impossible given this area's city center location.

In Models 9-14 with restricted capacity of renewable components, the sizes of solar PV and wind are predicted as technically feasible considering the roof area of the buildings suitable for the instalment of solar panels and the roof area suitable for instalment of wind turbines.

Table 9 Models with restricted renewable energy technologies: renewable fraction and $\mathrm{CO}_{2}$ emissions

\begin{tabular}{lccc}
\hline Model number & Model architecture $(\mathrm{CHP})$ & Renewable fraction/\% & $\mathrm{CO}_{2} \mathrm{emissions} /\left(\mathrm{kg} \cdot \mathrm{a}^{-1}\right)$ \\
\hline 9 & PV & 4.30 & 1344185 \\
10 & $\mathrm{PV}+$ battery & 4.30 & 1344154 \\
11 & Wind & 0.80 & 1350055 \\
12 & Wind + battery & 0.80 & 1350055 \\
13 & PV + wind & 5.00 & 1337592 \\
14 & $\mathrm{PV}+$ wind + battery & 5.10 & 1337616 \\
\hline
\end{tabular}




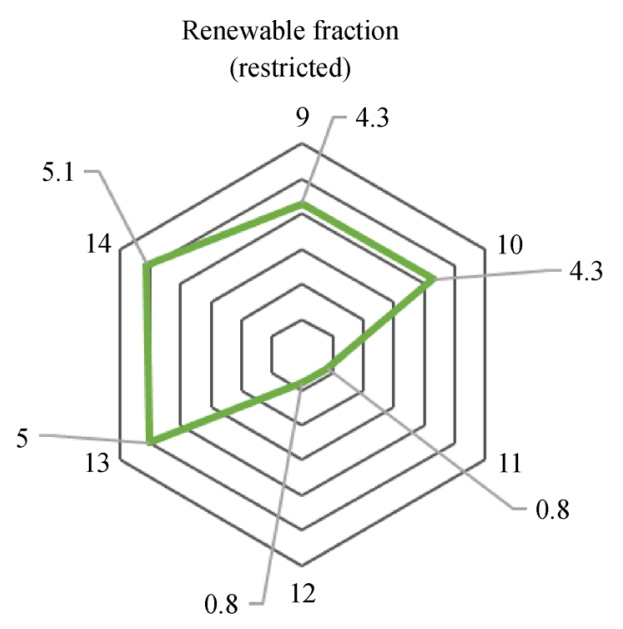

(a)

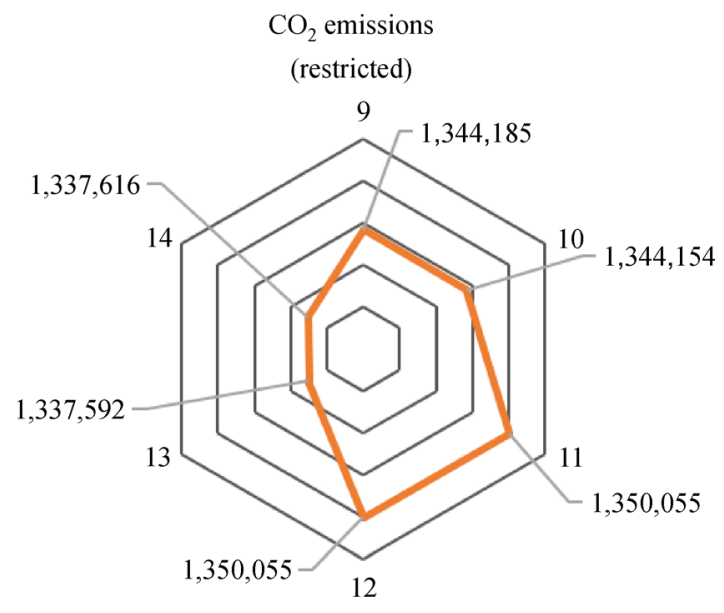

(b)

Fig. 10 (a) Renewable fraction and (b) $\mathrm{CO}_{2}$ emissions for models with restricted renewable energy technologies.

\subsection{Economic feasibility}

The economic feasibility of the proposed models was assessed with respect to the net present cost, the cost of generated energy, the operating cost, the investment cost as well as the percentage of energy generated by the system that was sold to the grid.

Models with no renewable energy technologies had the lowest net present cost, the lowest cost of generated energy, and the lowest cost of initial capital. Model 1 was designed to simulate the conventional energy system that is assumed to be in place in the housing estate under investigation. This does not require initial capital and performs better with respect to other costs than the model coupled with CHP. However, the model with CHP but no renewable technologies generates $25 \%$ excess of energy that is sold to the grid and the model without CHP has zero grid sales. Model 2 is, however, excluded as a possible solution for the housing estate on the basis that the energy sold to the grid is too low.

In models with unrestricted size of renewable components, the models coupled with the wind technology require the highest initial investment, are the most expensive to operate, and have the highest net present cost what is reflected in the cost of energy that is nearly double when compared to models with solar PV and over three times higher when compared to models without renewables. The models in this category have already been excluded due to the technical infeasibility for this site, but it is now excluded based on economic considerations as well. In addition, grid sales are the lowest in wind only models when compared to models with other configurations of renewable energy, with differences of about $3 \%$ (Model 5) and 13\% (Model 6).

Models with PV only and models with both types of renewable energy technologies also require significant initial investment, have high net present costs but their

Table 10 Models with the best overall performance

\begin{tabular}{|c|c|c|c|c|c|c|}
\hline \multirow{3}{*}{ Performance } & \multirow{3}{*}{ Category } & \multicolumn{5}{|c|}{ Best performing model } \\
\hline & & \multicolumn{2}{|c|}{$\begin{array}{l}\text { Unrestricted renewables } \\
\text { (excluding Models } 1 \& 2 \text { ) }\end{array}$} & \multicolumn{2}{|c|}{ Restricted renewables } & \multirow[t]{2}{*}{ Best overall } \\
\hline & & First choice & Second choice & First choice & Second choice & \\
\hline \multirow[t]{5}{*}{ Economic } & Net present cost & 3 & $4,7,8$ & 11 (marginal) & 12 (marginal) & 3 \\
\hline & Cost of energy & 3 & $4,7,8$ & 11 (marginal) & 12 (marginal) & 3 \\
\hline & Operating cost & 3 & $4,7,8$ & 9 (marginal) & 10 (marginal) & 3 \\
\hline & Initial capital & 3 & $4,7,8$ & 11 (marginal) & 12 (marginal) & 3 \\
\hline & Grid sales & 8 & $3,4,7$ & 14 (marginal) & 13 (marginal) & 8 \\
\hline \multirow[t]{2}{*}{ Environmental } & Renewable fraction & $3-8$ & - & 14 (marginal) & 13 (marginal) & $3-8$ \\
\hline & $\mathrm{CO}_{2}$ emission & 6 & - & 14 (marginal) & 13 (marginal) & $3-14$ \\
\hline Overall preferred & & \multicolumn{2}{|c|}{8} & \multicolumn{2}{|c|}{14} & 14 \\
\hline
\end{tabular}




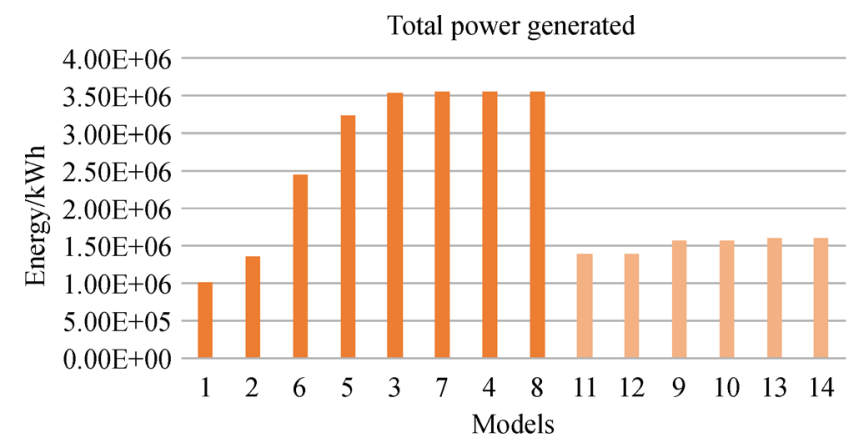

(a)

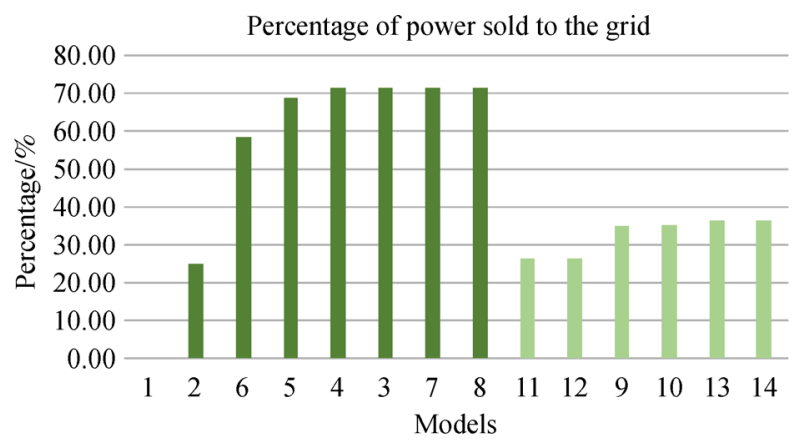

(b)

Fig. 11 Comparison of grid sales.

(a) Total power generated; (b) power sold to the grid.

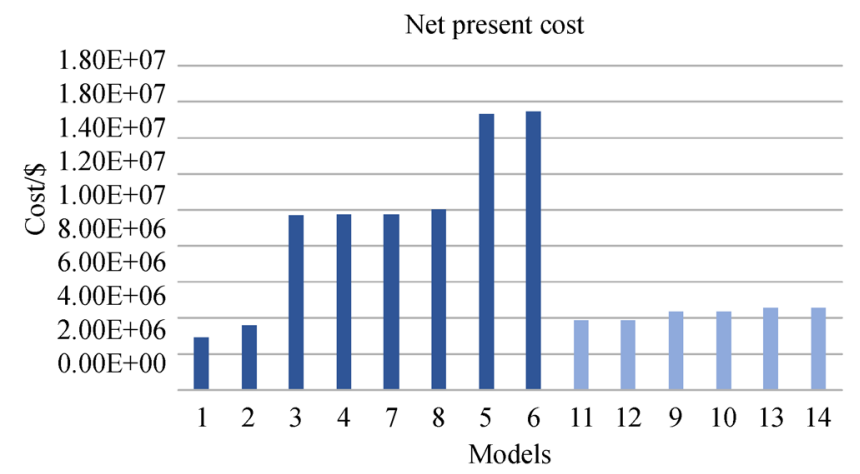

(a)

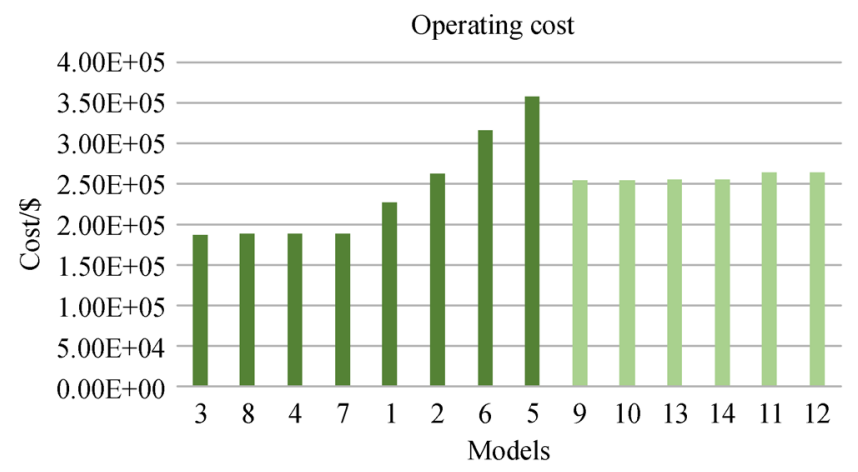

(c)

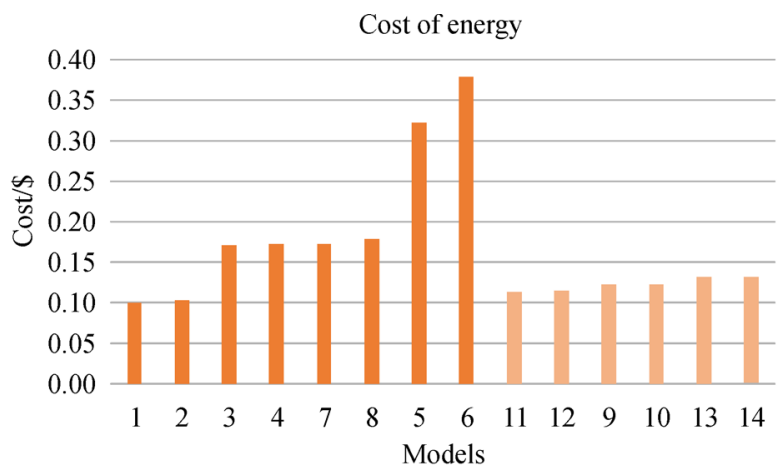

(b)

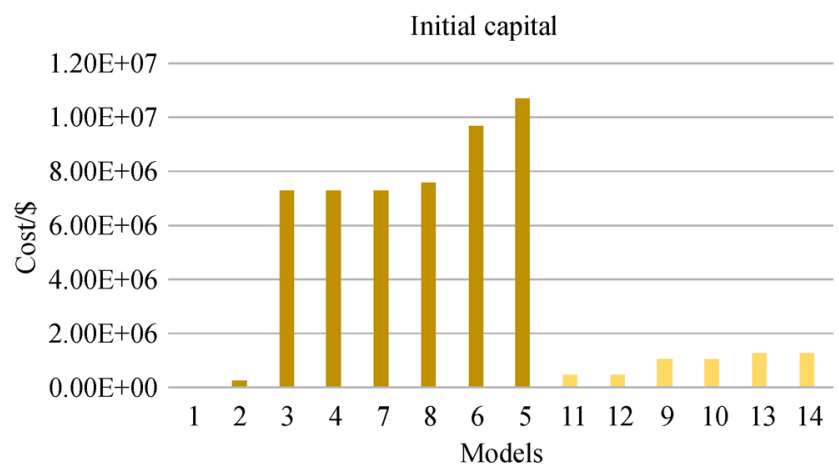

(d)

Fig. 12 Comparison of economic parameters.

(a) Net present cost; (b) cost of energy; (c) operating cost; (d) initial capital.

operating cost are the lowest and the grid sales are higher than in wind only models. The cost of energy in PV only models and combined models is about $40 \%$ higher than that generated by the systems without renewables, but it is approximately $46 \%$ to $54 \%$ lower than that generated by the system with wind turbines only.

In models with restricted capacity of renewable technologies, the wind only models have the lowest net present cost, the lowest cost of generated energy, and the lowest initial capital required, but the fixed wind capacity is only $10 \%$ of the fixed solar capacity in restricted models.
The wind only models also have the highest operating cost (although marginally so in comparison with other model) and the lowest grid sales. Therefore, Models 11 and 12 are excluded as possible solutions for the Stanhope Street site.

Models with combined renewable energy technologies have the highest initial cost, the highest cost of energy, and the highest initial capital, but they also have the highest grid sales, and the operating cost is lower than that in the wind only models. The PV only models have all the costs lower than the models with combined renewables and although the grid sales are also lower, the difference in grid 


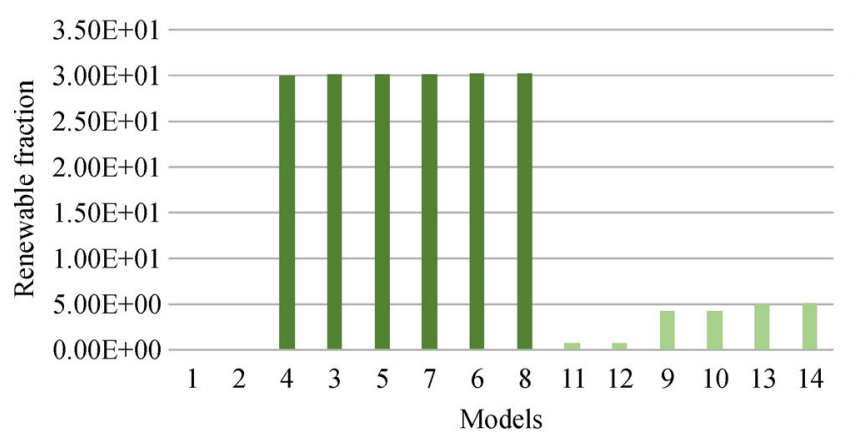

(a)

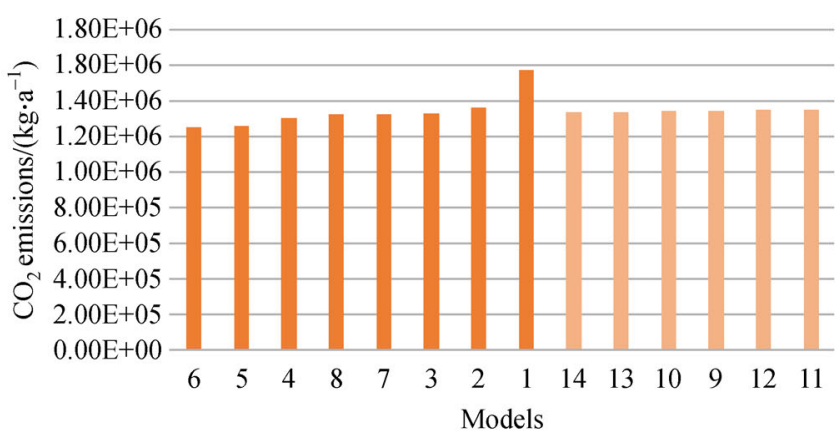

(b)

Fig. 13 Comparison of (a) renewable fraction and (b) $\mathrm{CO}_{2}$ emissions.

sales is about only $1.3 \%$ to $1.5 \%$ whereas the difference in costs is about $5 \%$ to $18 \%$. Considering this, Models 9 and 10 are excluded as possible solutions.

As it was expected, the fuel consumption by the boiler was significantly reduced as part of the heat demand was supplied by the 'waste' heat from CHP electricity generation. The difference in boiler fuel consumption between the model without CHP (Model 1) and the model with CHP (Model 2) was 30\% of the boiler fuel consumption with CHP. Two candidate models are left as possible solutions to the fuel poverty problem of Stanhope Street: Models 13 and 14.

\subsection{Environmental feasibility}

The environmental performance of the proposed models was compared with respect to the renewable fraction and the level of carbon dioxide emissions.

The carbon savings calculated with respect to the emission level of the model CHP and renewables were compared between the models (Table 11).

As it was expected, in models without renewable component the renewable fraction was zero and the $\mathrm{CO}_{2}$ emission was the highest; however, carbon saving with CHP in place (Model 2) was 6.4\% when compared to the model with conventional energy systems (Model 1).
In models with unrestricted renewables, Model 6 with the wind and battery storage technologies offered a renewable fraction of $30.1 \%$ and the highest carbon savings of $17.4 \%$. In models with combined renewables, Models 7 and 8 , also offered the highest renewable fraction $(30.2 \%$ and $30.1 \%$, respectively) but the carbon saving were approximately $8.8 \%$ lower when compared to Model 6. In PV models, Models 3 and 4, had a slightly lower renewable fraction and carbon savings of $8.9 \%$ lower than Model 6.

In models with restricted capacity of renewable components, the maximum value of renewable fraction was $5.10 \%$ observed in models with combined types of renewable technologies. These models also offered the highest carbon saving of $7.9 \%$. The models with wind only had the lowest renewable fraction of below $1 \%$ and the lowest carbon savings (approximately 7\%) but the capacity of wind was only $10 \%$ of the solar capacity, and the difference in carbon savings between wind only models and other models was less than $1 \%$. The PV only models had renewable fraction and carbon savings lower than the best performing models with combined renewables.

Although, the difference in renewable fraction between models with unrestricted and restricted renewables was significant (approximately 25\%), the maximum difference in carbon savings between two groups of models was maximum $11 \%$.

Table 11 Carbon saving with respect to conventional power system in the proposed models

\begin{tabular}{|c|c|c|c|c|}
\hline \multirow{3}{*}{$\begin{array}{l}\text { Model architecture } \\
\mathrm{CHP}+\text { grid }\end{array}$} & \multicolumn{4}{|c|}{ Carbon savings/\% } \\
\hline & \multicolumn{2}{|c|}{ Unrestricted renewables } & \multicolumn{2}{|c|}{ Restricted renewables } \\
\hline & Model 2 & 6.4 & \multicolumn{2}{|c|}{$\mathrm{N} / \mathrm{A}$} \\
\hline $\mathrm{CHP}+$ grid $+\mathrm{PV}$ & Model 3 & 8.5 & Model 9 & 7.4 \\
\hline $\mathrm{CHP}+$ grid $+\mathrm{PV}+$ battery & Model 4 & 8.5 & Model 10 & 7.4 \\
\hline $\mathrm{CHP}+$ grid + wind & Model 5 & 13.3 & Model 11 & 7.0 \\
\hline $\mathrm{CHP}+$ grid + wind + battery & Model 6 & 17.4 & Model 12 & 7.0 \\
\hline $\mathrm{CHP}+$ grid $+\mathrm{PV}+$ wind & Model 7 & 8.6 & Model 13 & 7.9 \\
\hline $\mathrm{CHP}+$ grid $+\mathrm{PV}+$ wind + battery & Model 8 & 8.7 & Model 14 & 7.9 \\
\hline
\end{tabular}


It needs to be noted that to achieve a minimum renewable fraction of $30 \%$, the energy systems have to be equipped with the capacity of renewable energy technologies of a minimum of $1328 \mathrm{~kW}$ for wind only models, a minimum of $2593 \mathrm{~kW}$ for solar only models and combined capacity of a minimum of $2575 \mathrm{~kW}$ for models with both solar and wind components. With the capacity of solar PV and wind technologies that was assessed as technically feasible for the site under investigation, the maximum achievable renewable fraction was $5.10 \%$.

What is most apparent from the analysis of the environmental impact data of this paper is that the renewable energy fraction does not significantly influence the reduction of $\mathrm{CO}_{2}$ emissions. It is not achievable to design a system for the site in this case study with a renewable fraction of $30 \%$, but the $\mathrm{CO}_{2}$ emissions can be reduced.

\subsection{Best overall feasibility}

The ideal configuration for energy generation would have technically feasible capacity of renewable energy technologies. In addition, it would have a low net present cost, a low cost of generated energy, a low operating cost, and a low initial capital. Furthermore, it would deliver the renewable fraction of a minimum of $30 \%$, the highest carbon savings, and it would generate significant income from selling the surplus of energy to the national grid. These are competing requirements and are unlikely to be found in any one configuration. Nonetheless, two systems have been identified in this paper with a potential to help alleviate fuel poverty: Model 13 and Model 14. In this case it is proposed that Model 14 be implemented since it has a battery pack consisting of 18 lithium-ion batteries with a 1 $\mathrm{kWh}$ rating each. Additional energy can be stored to be used during wind still night conditions. This will ensure that the system is more reliant on renewable energy components.

It can be assumed from the national data that 33 households $(11.1 \%)$ on the housing estate under investigation are living in fuel poverty. With CHP in place and with the renewable energy technologies on site for Model 14, a power of $582689 \mathrm{kWh} / \mathrm{a}$ are sold to the grid. Assuming a conservative selling price of $\$ 0.1 / \mathrm{kWh}$, the profit made would be $\$ 58268.9$. If $40 \%$ for example, of this profit could be passed through to the fuel poor tenants, the energy bills of the individual households could be reduced by $\$ 706$ per annum. This could go toward removing, or potentially eliminating, the household from fuel poverty conditions.

Model 14 was chosen as performing the best with regards to overall feasibility. It needs to be considered, however, that the overall feasibility of the proposed model is influenced by the investment costs and the technical performance of the components.

With renewable technologies market becoming more competitive and the technologies becoming cheaper, the price of renewable components would be expected to decrease. As a result, the economic feasibility of the best overall model would be improved, reflecting a lower investment cost, a lower replacement cost, and lower operating and maintenance costs.

If the price of the renewable components in the winning Model 14 was $20 \%$ lower than assumed, the net present cost would decrease from $\$ 4.54$ million to $\$ 4.33$ million, the investment cost would reduce from $\$ 1.24$ million to $\$ 1.05$ million, and the levelized cost of energy would be reduced from $\$ 0.132$ to $\$ 0.122$.

With expected technical advancement of currently available technologies and the improvement of the performance of the components, the output would be higher in influencing the overall technical feasibility of the proposed models. However, it is possible that with improved efficiency, the lifetime of the components could decrease, leading to an increased net present cost of the project resulting from higher replacement, operation, and maintenance costs.

As the housing estate under investigation is in the city center, close to an acute NHS hospital on the helicopter flight path and the space on the estate is limited, it would not be possible to obtain a planning permission for deployment of a ground mounted wind turbine. However, with a larger wind turbine in place, the grid sales would be significantly higher and the levelized cost of energy lower, offering a greater saving on energy bills paid by the tenants.

With a $1.5 \mathrm{MW}$ wind turbine replacing 30 (30) rooftop wind turbines with a capacity of $1 \mathrm{~kW}$ each in the best overall model (Model 14), the total production of electricity from wind would increase from $43094 \mathrm{kWh} / \mathrm{a}$ to $4041999 \mathrm{kWh} / \mathrm{a}$, with a levelized cost of the energy produced from wind decreasing from $0.478 \$ / \mathrm{kWh}$ to $0.0728 \$ / \mathrm{kWh}$. The grid sales would increase from 582689 $\mathrm{kWh} / \mathrm{a}(36.4 \%)$ for the best overall model to 3570256 $\mathrm{GWh} / \mathrm{a}(77.8 \%)$ for a model with $1.5 \mathrm{MW}$ in place, lowering the unit price of the energy calculated for the entire system from $0.132 \$ / \mathrm{kWh}$ to $0.049 \$ / \mathrm{kWh}$. This shows substantial reduction in the levelized cost of the energy of the system with a larger wind component but given the constraints of the site, such solution is not feasible.

The proposed size of the CHP $(150 \mathrm{~kW})$ was chosen to benefit the site under investigation and to generate profit from selling the excess of electricity back to the grid. By replacing the $150 \mathrm{~kW} \mathrm{CHP}$ in the winning Model 14 with the $600 \mathrm{~kW}$ CHP, the grid sales would increase from $582689 \mathrm{kWh} / \mathrm{a}$ to $2577481 \mathrm{kWh} / \mathrm{a}$ and the thermal excess would increase from $201 \mathrm{kWh} / \mathrm{a}$ to $134855 \mathrm{kWh} / \mathrm{a}$. A system with a larger CHP in place could potentially serve as a decentralised CHP in the district heating network and serve as a part of the decarbonised energy system as presented in the Heat Roadmap Europe Efficiency (HRE- 
EE) strategy [20], reducing heat transmission losses, reducing the number of individual fossil fuel boilers in the neighboring area (serving other residential, community, and commercial buildings), and contributing to the more efficient and environmental friendly energy system. The proposed system could further benefit the local and national energy system by contributing to its decarbonization by replacing natural gas with biomethane or biomass to fire the CHP. With biomethane replacing natural gas in the winning Model 14, carbon dioxide emission would be reduced almost 3-fold, from $1377616 \mathrm{~kg} / \mathrm{a}$ to $481747 \mathrm{~kg} / \mathrm{a}$. Such transition would also reduce fossil fuel reliance of the energy system and contribute to the existing building stock becoming low energy buildings.

The proposed system can potentially attract an income not only from selling the surplus of energy to the grid but also by becoming a supplier to the neighborhood and even city-wide. However, to achieve that purpose, an instant optimisation of both generation and supply of energy is required. A smart control of the energy supply and demand, as well as integration of different energy sectors are essential measures of the Smart Energy System. By installing electrical vehicle charging points on the housing estate under investigation and locally, onsite power generation can be interconnected with the transport system, further supporting the transition toward the Smart Energy System.

To address the socio-economic problem of fuel poverty at regional or even national level, the benefits of decarbonised energy systems need to be analyzed. With redesigned, cost-effective, and fuel-efficient energy systems such as the Smart Energy System, potential energy savings and their financial impact need to be assessed to propose a technically feasible solution to fuel poverty that is in line with decarbonisation of the energy sector and contributes to its transition to $100 \%$ renewable energy.

\section{Conclusions}

Models with CHP in place, have a potential to help alleviating fuel poverty. The electricity generated with the use of a CHP unit fueled with natural gas is cheaper than that generated in power plants due to the difference between tariff levels for gas and electricity supply with gas having a lower price per unit of energy. The generation and transition losses are also minimized with on-site generation. The financial benefit of having a CHP on site is associated with making electricity savings when the electric load is met with the electricity generated by the CHP rather than purchased from the national grid. In addition, as it was demonstrated in this paper, the CHP system generated a surplus of power that is sold to the grid. Electricity savings and grid sales could be potentially used to offset the cost of energy incurred by tenants in fuel poverty. Models combining CHP and renewable energy technologies have a potential to generate even more electricity savings and grid sales. The electricity generated from on-site renewable energy technologies further minimize the amount of energy purchased from the grid.

However, the potential for electricity savings and grid sales is directly related to the capacity of the renewable energy technologies. However, as the capacity of renewables increases, the net present cost increases. Besides, a higher capacity of renewable component may not be technically feasible due to limited space in site and environmental and planning permission issues.

Models with restricted size of renewable energy component delivered grid sales. However, they were only half the level of grid sales achievable with unrestricted models. Restricted models were technically and economically feasible, but the maximum renewable fraction was six times lower than the required of $30 \%$. Ideally, a hybrid renewable energy system with a potential to help to alleviate fuel poverty would be technically and economically feasible, and in line with the emission and renewable fraction targets set up by the Government to address the pressing climate change issue.

The results of this paper demonstrate that achieving substantial grid sales (approximately 70\%) and meeting the target of $30 \%$ electricity generations from renewable energy sources such as solar and onshore wind are possible but not technically feasible on a housing estate under investigation that is in densely populated area. The capacity of renewable technologies with $2.5 \mathrm{MW}$ to 2.7 MW for solar PV and 1.3 MW to 1.4 MW for onshore wind exceed the capacity that can be installed on the site. Moreover, the cost associated with such capacities of renewable components is substantial with the net present cost of the projects between $\$ 9.70$ million and $\$ 15.3$ million and the initial capital in a range of $\$ 7.26$ million and $\$ 10.7$ million. Without significant financial support from the Government, it would be difficult to make high renewable fraction models financially feasible and attractive for landlords and potential investors.

Additional investment into research and development is necessary to increase the yield of existing renewable technologies (hence reducing the size for additional on-site capacity) and to uncover new renewable technology options to add to the mix of available applications.

Open Access This article is licensed under a Creative Commons Attribution 4.0 International License, which permits use, sharing, adaptation, distribution and reproduction in any medium or format, as long as you give appropriate credit to the original author(s) and the source, provide a link to the Creative Commons licence, and indicate if changes were made.

The images or other third party material in this article are included in the article's Creative Commons licence, unless indicated otherwise in a credit line to the material. If material is not included in the article's Creative Commons licence and your intended use is not permitted by statutory regulation or exceeds the permitted use, you will need to obtain permission directly from the copyright holder. 
To view a copy of this licence, visit http://creativecommons.org/licenses/ by $/ 4.0 \%$.

\section{References}

1. Department for Business (UK). Energy \& industrial strategy. Committee on fuel poverty annual report 2018. 2020-05-16, available at the website of assets.publishing.service.gov.uk

2. Department for Business (UK). Energy \& industrial strategy. Fuel poverty detailed tables 2018. 2019-03-29, available at the website of gov.uk

3. Liddell C, Morris C, McKenzie S J P, et al. Measuring and monitoring fuel poverty in the UK: national and regional perspectives. Energy Policy, 2012, 49: 27-32

4. Newcastle City Council (UK). Newcastle upon Tyne warm homes, healthy lives. An affordable warmth strategy seeking your support \& action. 2019-03-25, available at the website of newcastle.gov.uk

5. Committee on Climate Change (UK). UK housing: fit for the future? 2019-04-02, available at the website of theccc.org.uk

6. Department for Business (UK). Energy \& Industrial Strategy (2018e): sub-regional fuel poverty, 2016 data. 2019-03-29, available at the website of gov.uk

7. Department for Business (UK). Energy \& Industrial Strategy (2018c): fuel poverty detailed tables 2018. 2019-03-29, available at the website of gov.uk

8. Ministry of Housing (UK). Communities \& Local Government (no date): find energy grants and ways to improve your energy efficiency. 2019-05-10, available at the website of gov.uk

9. Webb J. Improvising innovation in UK urban district heating: the convergence of social and environmental agendas in Aberdeen. Energy Policy, 2015, 78: 265-272

10. Department of Energy \& Climate Change. The UK Low Carbon Transition Plan: National strategy for climate and energy. 2019-0329, available at the website of gov.uk

11. Drysdale D, Mathiesen B V, Paardekooper S. Transitioning to a $100 \%$ renewable energy system in Denmark by 2050: assessing the impact from expanding the building stock at the same time. Energy Efficiency, 2019, 12(1): 37-55

12. Tian Z, Seifi A. Reliability analysis of hybrid energy system. International Journal of Reliability Quality and Safety Engineering, 2014, 21(3): 1450011

13. Raji A K, Luta D N. Modelling and optimization of a community microgrid components. Energy Procedia, 2019, 156: 406-411

14. Lund $\mathrm{H}$, Werner $\mathrm{S}$, Wiltshire R, et al. 4th Generation District Heating (4GDH): integrating smart thermal grids into future sustainable energy systems. Energy, 2014, 68: 1-11

15. Abdilahi A M, Yatim A H M, Mohd Mustafa M W, et al. Feasibility study of renewable energy-based microgrid system in Somaliland's urban centers. Renewable \& Sustainable Energy Reviews, 2014, 40: 1048-1059

16. Islam M T, Huda N, Saidur R. Current energy mix and technoeconomic analysis of concentrating solar power (CSP) technologies in Malaysia. Renewable Energy, 2019, 140: 789-806
17. Carbon Trust (UK). Introducing combined heat and power: a new generation of energy and carbon savings. 2019-03-07, available at the website of carbontrust.com

18. Mokhtara C, Negrou B, Bouferrouk A, et al. Integrated supplydemand energy management for optimal design of off-grid hybrid renewable energy systems for residential electrification in arid climates. Energy Conversion and Management, 2020, 221: 113192

19. Eriksson E L V, Mac E, Gray A. Optimization of renewable hybrid energy systems - a multi-objective approach. Renewable Energy, 2019, 133: 971-999

20. Yang F, Xia X. Techno-economic and environmental optimization of a household photovoltaic-battery hybrid power system within demand side management. Renewable Energy, 2017, 108: 132-143

21. Adefarati T, Bansal R C. Reliability, economic and environmental analysis of a microgrid system in the presence of renewable energy resources. Applied Energy, 2019, 236: 1089-1114

22. Department for Business (UK). Energy \& Industrial Strategy (2018a): combined heat and power. 2019-05-02, available at the website of gov.uk

23. Department for Business (UK). Energy \& Industrial Strategy (2019a): combined heat and power incentives. 2019-04-20, available at the website of gov.uk

24. Ataei A, Choi J, Ziabakhsh N, et al. Integration of a photovoltaic system and a combined heat and power generator in an educational building using eQuest and HOMER Models. American Journal of Renewable and Sustainable Energy, 2015, 1(3): 106-114

25. Connolly D, Lund H, Mathiesen B V, et al. Heat roadmap Europe: combining district heating with heat savings to decarbonize the EU energy system. Energy Policy, 2014, 65: 475-489

26. Mathiesen B V, Lund H, Connolly D, et al. Smart energy systems for coherent $100 \%$ renewable energy and transport solutions. Applied Energy, 2015, 145: 139-154

27. Drysdale D, Vad Mathiesen B, Lund H. From carbon calculators to energy system analysis in cities. Energies, 2019, 12(12): 2307

28. HOMER Energy. Tour of HOMER Pro. 2019-04-15, available at the website of youtube.com

29. Belu R, Chiou R, Ghaisas K, et al. Teaching renewable energy system design and analysis with HOMER. In: 121st ASEE Annual Conference \& Exposition, Indianapolis, USA, 2014

30. Office of Gas and Electricity Markets (UK). Typical domestic consumption values. 2019-04-20, available at the website of ofgem.gov.uk

31. NASA Prediction of Worldwide Energy Resources. Surface meteorology and solar energy (SSE-release 6.0) databases. 201905-10, available at the website of power.larc.nasa.gov

32. Alotaibi D M, Akrami M, Dibaj M, et al. Smart energy solution for an optimised sustainable hospital in the green city of NEOM. Sustainable Energy Technologies and Assessments, 2019, 35: 3240

33. Gökçek M, Kale C. Techno-economical evaluation of a hydrogen refuelling station powered by wind-PV hybrid power system: a case study for İzmir-Çeşme. International Journal of Hydrogen Energy, 2018, 43(23): 10615-10625 